\title{
A Ineficácia da Tutela Multinível dos Direitos SOCIAIS NA UNIÃO EUROPEIA
}

\author{
Alice Rocha da Silva* \\ Matheus Passos Silva**
}

\begin{abstract}
1 Introdução. 2 Os direitos fundamentais em perspectiva nacional e supranacional. 2.1 Dos direitos nacionais ao direito supranacional. 2.2 O constitucionalismo multinível na união europeia. 2.3 Os direitos fundamentais no constitucionalismo multinível do espaço europeu. 2.3.1 A carta dos direitos fundamentais da união europeia. 2.3.2 A convenção europeia dos direitos do homem. 2.4 A tutela multinível dos direitos fundamentais. 3 Os riscos da tutela multinível. 3.1 O diálogo judicial como mecanismo para se (tentar) evitar conflitos entre órgãos jurisdicionais. 3.2 A ausência de diálogo judicial entre tribunais: o parecer 2/13. 4 Conclusão. Referências.
\end{abstract}

\section{RESUMO}

A existência de três níveis distintos de proteção dos direitos sociais na União Europeia - internacional, regional e nacional - leva à pressuposição de que existem inúmeras vantagens em tal arranjo jurídico. De maneira sintética, pode-se afirmar que existiria uma verdadeira complementaridade entre tais sistemas, já que as insuficiências de um poderiam ser sanadas por outro. Contudo, o sistema envolve riscos, especialmente quando se considera que tais ordens jurídicas, por serem distintas, nem sempre estarão em harmonia, ainda que se utilizem dos mesmos conceitos. Nesse sentido, o objetivo deste texto é analisar alguns riscos em relação à tutela multinível dos direitos fundamentais, com foco nos direitos sociais. Para tanto, parte-se da metodologia de análise do surgimento da tutela multinível dos direitos fundamentais e de sua conceituação teórica, para, em seguida, serem apresentados os riscos da tutela multinível, especialmente aqueles decorrentes da falta de diálogo judicial entre os tribunais envolvidos.

Palavras-chave: Tutela multinível. União Europeia. Direitos sociais. Parecer 2/13.

* Professora do Programa de Mestrado e Doutorado em Direito do Centro Universitario de Brasilia - UniCEUB. Doutora em Direito pela Universite d'Aix-Marseille III, Franca. Mestre em Direito pelo UniCEUB. Graduada em Direito pelo UniCEUB e em Ciencia Politica e Relacoes Internacionais pela Universidade de Brasilia.E-mail: <rochaalice@yahoo.com.br>.

** Doutorando em Direito Constitucional pela Faculdade de Direito da Universidade de Lisboa. Pesquisador voluntário do CEDIS, da Faculdade de Direito da Universidade Nova de Lisboa. Professor da Faculdade Projeção. Pesquisador CAPES - Proc. No 1791/15-0. Currículo completo disponível em < http://lattes.cnpq.br/4314733713823595>. Email: <contato@profmatheus.com>. 


\section{INTRODUÇÃO}

As alterações político-jurídicas do século XX que fizeram surgir certos organismos internacionais trouxeram consigo a criação de uma chamada tutela multinivel dos direitos. Em outras palavras, a defesa dos direitos do cidadão - especialmente os fundamentais, incluídos os sociais - não pode mais ficar a cargo exclusivamente da instituição Estado, especialmente quando se considera que essa instituição é capaz de violar tais direitos.

Nesse contexto de tutela multinível dos direitos, considera-se que o espaço geográfico europeu seja privilegiado por dois motivos principais. O primeiro deles diz respeito ao histórico, ou seja, ao fato de que o espaço europeu é aquele que há mais tempo traz como um de seus principais valores jurídicos a tutela multinível dos direitos fundamentais. O segundo diz respeito ao fato de que, no espaço europeu, se situam dois dos principais mecanismos responsáveis pela tutela desses direitos, quais sejam, a Convenção Europeia dos Direitos do Homem, por um lado, e a Carta de Direitos Fundamentais da União Europeia, por outro.

A existência de três níveis distintos de proteção dos direitos fundamentais - acresça-se aos dois citados o nível nacional - leva à pressuposição de que existem inúmeras vantagens em tal arranjo jurídico. De maneira sintética, pode-se afirmar que existiria uma verdadeira complementaridade entre tais sistemas, já que as insuficiências de um poderiam ser sanadas por outro. Contudo, o sistema envolve riscos, especialmente quando se considera que tais ordens jurídicas, por serem distintas, nem sempre estarão falando a respeito do mesmo assunto, ainda que se utilizem das mesmas palavras. Nesse sentido, o objetivo deste texto é o de analisar alguns riscos em relação à tutela multinível dos direitos fundamentais, com foco nos direitos sociais.

Para tanto, parte-se da metodologia de analise do surgimento da tutela multinível dos direitos fundamentais e de sua conceituação teórica, para, em seguida, serem apresentados os riscos da tutela multinível, especialmente aqueles decorrentes da falta de diálogo judicial entre os tribunais envolvidos.

\section{OS DIREITOS FUNDAMENTAIS EM PERSPECTIVA NACIONAL E SUPRANACIONAL}

O entendimento da tutela multinível dos direitos sociais pressupõe a compreensão do fato de que os direitos fundamentais não mais se limitam às tradicionais fronteiras entre os Estados. Por outras palavras, a defesa dos direitos fundamentais e sua garantia na realidade prática do cidadão situa-se atualmente para além do trinômio "soberania-território-povo" que caracteriza o conceito tradicional de Estado, de maneira a ser competência também de outras instituições - não apenas particulares, mas também as sui generis, como a União Europeia ${ }^{1}$ - a garantia de tais direitos. 


\subsection{Direitos nacionais ao direito supranacional}

A garantia dos direitos fundamentais é, em conjunto com a democracia e com a separação dos poderes, um dos pilares do chamado Estado de direito democrático, o qual, por sua vez, corresponde à forma de organização típica dos Estados ocidentais na atualidade. Nesse contexto, vale destacar que não se pode pressupor apenas a garantia, ou a presença, desses direitos fundamentais no texto constitucional, mas também sua efetiva concretização na realidade prática.

Nesse sentido, importa destacar que, em sua origem, os direitos fundamentais tinham como objetivo central a não intromissão do Estado na vida privada dos cidadãos. Possuindo caráter claramente liberal, a chamada primeira dimensão de direitos fundamentais tinha em vista a proteção da liberdade individual não apenas no sentido de se evitar que o Estado interviesse nessa esfera, mas também no de se evitar que outros cidadãos interferissem nos negócios privados dos demais².

O desenvolvimento histórico do século XIX na Europa, contudo, mostrou que a garantia apenas da liberdade individual não seria suficiente para a concretização efetiva de todas as potencialidades do ser humano enquanto tal. Dessa maneira, no final do século XIX e início do século XX, surgem os chamados direitos de segunda dimensão ou direitos sociais, econômicos e culturais e que possuíam caráter claramente social. Tais direitos, surgidos como uma resposta do pensamento europeu ocidental à eventual influência da Revolução Russa na Europa ocidental ${ }^{3}$, buscam a garantia de um nível mínimo de vida ao cidadão, cabendo, dessa maneira, ao Estado a realização de um mínimo de justiça social ${ }^{4}$.

Nessa toada, se, por um lado, o "breve século XX" ${ }^{5}$ consolidou a ideia de democracia surgida no século XIX, por outro, trouxe à tona um ideal que se tornaria, possivelmente, a sua principal marca, qual seja, o da dignidade humana. Uma vez que os horrores do nazismo precisavam ser evitados, a dignidade humana se tornou o norte que passou a definir, em conjunto com o ideal democrático, a atuação dos Estados. Desta feita, o conjunto dos direitos fundamentais passou a ser concretizado pelo Estado com o objetivo central de se garantir a dignidade humana, ainda que cada um definisse, em sua própria Constituição, seus respectivos direitos fundamentais bem como a forma de concretizá-los.

Contudo, a vida do cidadão - protegida pelos direitos fundamentais - não se limita mais às fronteiras do tradicional "Estado-nação", ou seja, não está mais restrita a normas internas criadas e aplicadas exclusivamente pelo Estado. Por um lado, a expansão da proteção dos direitos fundamentais a áreas que vão além da tradicional dicotomia "indivíduo-sociedade" gerou a necessidade de se rever não apenas os próprios direitos em si mesmos, mas também - e principalmente - os responsáveis pela garantia efetiva desses mesmos direitos. A título de exemplo, a partir do momento em que a proteção do meio ambiente passou a ser um direito fundamental tutelado pelo Estado, passou-se a questionar qual Estado seria o responsável por tal tutela, especialmente quando se considera o princípio da 
ubiquidade do direito ambiental no sentido em que os danos ambientais são sentidos por todos os seres humanos independentemente de quem os causou.

Por outro lado, mas em consonância com a ideia de expansão da responsabilidade estatal, uma vez que fenômenos sociais interferem cada vez mais na vida de milhões de indivíduos - fenômenos como a globalização, por um lado, e a disseminação da possibilidade de comunicação instantânea, por outro -, a proteção dos direitos fundamentais não pode mais ficar apenas nas mãos de um único Estado. Apresenta-se claramente como necessária a coordenação de esforços entre Estados diferentes no sentido de se prover a maior proteção possível à pessoa humana, especialmente se considera que sua dignidade é o valor mais importante a ser protegido ${ }^{7}$.

Além disso, impende destacar que o próprio Holocausto provou que o Estado pode, ele próprio, infringir os direitos fundamentais que ele mesmo garante $^{8}$, e isto a despeito de todas as eventuais garantias jurídicas - inclusive constitucionais - de que dispõe o cidadão. A Europa percebeu, desde cedo, esse perigo, talvez até mesmo por ter sido em seu próprio território que as violações aos direitos fundamentais, provavelmente as mais graves até o momento na história humana recente, ocorreram. Nesse sentido, verificou-se, após o fim da Segunda Guerra Mundial, não apenas o surgimento dos direitos de terceira dimensão mas também, e mais importante, o surgimento do que se convencionou chamar de constitucionalismo multinivel $^{9}$, conceito que ganha destaque e relevância especialmente no espaço geográfico europeu.

\section{$2.2 \mathrm{O}$ constitucionalismo multinível na união europeia}

Por constitucionalismo multinível entende-se o processo de (re)organização dos Estados no âmbito da Europa que leva ao surgimento de novas formas de governança, com destaque especial para a governança compartilhada entre Estados e instituições. Uma vez que os cidadãos passam a possuir múltiplas identidades - uma vinculada à sua cidade, outra vinculada ao seu país (nacionalidade) e uma última vinculada à própria União Europeia ${ }^{10}$ - surge a necessidade de haver intensa coordenação entre as esferas de governo respectivas a cada uma dessas instâncias identitárias ${ }^{11}$. Tal coordenação se afigura como necessária a partir do momento em que se tenha em mente aquele a quem a governança se dirige - em última instância, o cidadão.

O conceito de constitucionalismo multinível se fundamenta em quatro elementos básicos. O primeiro deles se refere ao necessário caráter pós-nacional das constituições atuais, ou seja, à situação em que não apenas Estados possuem constituições, mas também as têm - seja no aspecto formal, seja principalmente no aspecto material - instituições supra e internacionais ${ }^{12}$, como é o caso, na atualidade, da União Europeia, cujos tratados correspondem a uma constituição em sentido material, ainda que não formal ${ }^{13}$.

Em segundo lugar, destaca-se a posição central que o cidadão tem no constitucionalismo multinível. A União Europeia, entendida como instituição 
sui generis ${ }^{14}$, legitima-se com base na vontade dos cidadãos europeus, os quais, por meio de seus respectivos representantes, atuaram na criação de uma nova "camada de constitucionalidade" correspondente às esferas de atuação da própria União. Por outras palavras, instituíram-se os Tratados e, com base nestes, surgiu, por um lado, a ideia de "cidadão da União Europeia” e, por outro, as necessárias instituições supranacionais responsáveis por garantir e proteger os direitos desses mesmos cidadãos ${ }^{15}$.

O terceiro aspecto relevante do constitucionalismo multinível no âmbito europeu se refere à, cada vez mais, crescente interpenetração do direito europeu nos direitos nacionais e vice-versa, o que leva à verdadeira interdependência entre as diferentes esferas de constitucionalidade. Por um lado, ressalta-se que a União Europeia é uma criação de seus próprios Estados-membros, o que torna possível afirmar que as leis europeias correspondem a um amálgama das legislações nacionais; por outro, com o desenvolvimento da própria União Europeia e com o estabelecimento de relativa, mas crescente, autonomia de sua parte frente aos Estados-membros, as legislações nacionais, cada vez mais, precisam se abrir à legislação europeia, não apenas no sentido de transpô-la para a ordem jurídica interna ${ }^{16}$ mas também no sentido de executá-las ${ }^{17}$.

Por fim, importa destacar a já citada multiplicidade de identidades do cidadão europeu. Deixando-se de lado as subdivisões internas dos Estados-membros da União Europeia, é possível afirmar que o cidadão europeu possui duas identidades, quais sejam, a identidade nacional, vinculada ao seu país, e a identidade europeia. Ambas identidades são juridicamente estabelecidas, em um caso pela própria constituição interna do Estado-membro, e em outro pelo art. 20 do Tratado sobre o Funcionamento da União Europeia (TFUE). Como deixa claro o texto deste artigo, a identidade europeia não substitui a nacional, mas antes acresce-se a esta, de maneira a corresponder às diferentes comunidades político-jurídicas - e ainda culturais - das quais o indivíduo participa ${ }^{18}$.

Ainda acerca do constitucionalismo multinível, importa chamar a atenção para uma de suas características, qual seja, a de ausência de hierarquia no relacionamento entre os Estados-membros e a União Europeia. Por outras palavras, o ordenamento jurídico dos Estados-membros coexiste com o ordenamento jurídico da União Europeia sem haver supremacia de um sobre outro - especialmente quando se considera que os Tratados estabelecem as competências específicas de cada jurisdição cujo objetivo é trabalhar em harmonia para a concretização dos direitos dos cidadãos ${ }^{19}$.

2.3 Os direitos fundamentais no constitucionalismo multinível do espaço europeu

Devido à sua história de integração regional iniciada logo após a Segunda Guerra Mundial, é inegável que os Estados europeus como um todo e a União Europeia em particular se encaixam claramente no contexto do constitucionalismo multinível. Mais além, a despeito de outras instituições de âmbito supranacional 
eventualmente surgidas em outras partes do globo, a União Europeia se caracteriza como sendo o exemplo mais avançado de constitucionalismo multinível existente na atualidade ${ }^{20}$, já que o processo vem sendo realizado ininterruptamente ao longo de várias décadas.

Uma das principais funções no âmbito de um sistema constitucional tradicional - isto é, interno aos Estados - é prever e garantir os direitos fundamentais dos cidadãos. É a presença dos direitos fundamentais, em conjunto com a noção de rule of law e com a premissa da separação de poderes, que faz com que determinado Estado possa vir a ser considerado um Estado de direito democrático nos moldes atuais. Sem a garantia desses direitos, infringe-se aquele que é o bem último tutelado pelo Estado, qual seja, a dignidade humana.

A existência dos direitos fundamentais em um sistema constitucional tradicional é algo já estabelecido, especialmente no que concerne à tutela desses direitos fundamentais. Em outras palavras, o cidadão, utilizando-se do princípio do juiz natural, terá sua petição apreciada por um tribunal competente previamente definido na $\mathrm{lei}^{21}$. Por sua vez, parece claro que a competência por prover não apenas os direitos fundamentais em termos formais mas também em termos materiais é do Estado ${ }^{22}$, cabendo a este a responsabilidade em caso de não cumprimento de seus deveres de provedor de determinado direito fundamental ${ }^{23}$.

\subsubsection{A Carta dos Direitos Fundamentais da União Europeia}

Ora, se é pressuposto de uma constituição a previsão e a garantia de direitos fundamentais e se os tratados da União Europeia formam, em termos materiais, uma constituição, torna-se inegável a necessidade de também a União Europeia, além de seus Estados-membros, garantir os direitos fundamentais de seus cidadãos. Nesse sentido, a garantia dos direitos fundamentais dos cidadãos europeus ganhou ímpeto ${ }^{24}$ a partir da entrada em vigor do Tratado da União Europeia (TUE), em 2009, (Tratado de Lisboa), o qual trouxe, em seu art. $6^{\circ}, \mathrm{n}^{\mathrm{o}}$ 1 , o reconhecimento dos direitos fundamentais conforme enunciados na Carta dos Direitos Fundamentais da União Europeia (CDFUE ou Carta), passando esta a ter valor jurídico igual ao dos demais Tratados - ou seja, passou a ser vista como direito originário da União ${ }^{25}$.

O art. 51, no 1 da Carta, traz seus destinatários. Destacam-se explicitamente dois grupos, quais sejam, em primeiro lugar, as instituições, os órgãos e os organismos da União dentro daquilo que lhes couber, considerando-se as competências estabelecidas nos Tratados, e com base no princípio da subsidiariedade. Em segundo lugar, apresentam-se os Estados-membros como destinatários da Carta, mas apenas quando estiverem aplicando o direito da União de acordo com suas próprias competências, as quais também são estabelecidas pelos Tratados ${ }^{26}$, ou seja, tem-se que o catálogo de direitos fundamentais contido na Carta podem ser invocados tanto frente ao Tribunal 
de Justiça da União Europeia quanto nos tribunais nacionais quando estes atuarem na aplicação do direito da União ${ }^{27}$.

É importante destacar que a CDFUE não tem por objetivo criar novos direitos, mas sim o de codificar os direitos já existentes no espaço comum dos Estados-membros, direitos estes surgidos a partir das tradições constitucionais comuns aos Estados-membros ${ }^{28}$. Dessa maneira, ainda que correspondendo ao papel tradicional dos direitos fundamentais em uma constituição, a CDFUE serve para limitar os poderes da União em si mesma, além de orientar as políticas propostas pela União com base na garantia aos indivíduos do exercício de seus direitos de liberdades e também de seus direitos sociais. Ainda, destaca-se o papel de "guia" exercido pela CDFUE na interpretação da legislação europeia, servindo de referência importante para os tribunais ${ }^{29}$.

A tutela dos direitos fundamentais dentro da União Europeia é feita pelo Tribunal de Justiça da União Europeia (TJUE), o qual possui a competência devida para garantir a proteção dos direitos fundamentais no âmbito da União - competência esta que se vincula não apenas à apreciação da legislação da União mas também à das ações realizadas pelos Estados-membros para pôr em prática o direito originário e o direito derivado. Além do TJUE, também os tribunais nacionais - sejam os constitucionais, sejam os ordinários - possuem a prerrogativa de interpretar e aplicar as normas da União que se refiram aos direitos fundamentais ${ }^{30}$, conforme suas prerrogativas estabelecidas nos Tratados.

\subsubsection{A Convenção Europeia dos Direitos do Homem}

Importa destacar que o Tratado de Lisboa trouxe outro elemento importante no que concerne à defesa dos direitos fundamentais para além da equiparação jurídica da CDFUE aos Tratados: foi a possibilidade dada à União Europeia de aceder à Convenção Europeia dos Direitos do Homem $(\mathrm{CEDH})$, conforme previsto no art. $6^{\circ}, n^{\circ} 2$, do TUE ${ }^{31}$. Nesse sentido, ainda que a entrada da União Europeia à CEDH não seja automática - ou seja, não é porque existe a previsão no Tratado que tal acesso automaticamente acontece(rá) -, parece ser inegável que a existência de tal possibilidade corresponde a um reforço da defesa dos direitos fundamentais no espaço europeu ${ }^{32}$, especialmente quando se considera o relevante papel simbólico a ser desempenhado pela própria União Europeia no sentido de reforçar a defesa e a garantia dos direitos fundamentais dos cidadãos.

A CEDH, em vigor desde 1953, corresponde a um catálogo de direitos humanos que, grosso modo, são análogos aos tradicionais direitos fundamentais de primeira dimensão, ou seja, aos direitos civis e políticos. Nesse sentido, poder-se-ia afirmar que a CEDH tem uma proteção mais restritiva do que a CDFUE, já que esse documento engloba direitos de segunda e de terceira dimensões ${ }^{33}$. Da mesma maneira, a CEDH protegeria menos direitos do que, por exemplo, a Constituição portuguesa que, assim como a CDFUE, também prevê a defesa dos direitos de segunda e terceira dimensões ${ }^{34}$. 
É importante destacar que, com base na CEDH, o acesso ao Tribunal Europeu dos Direitos do Homem (TEDH) pode ser feito diretamente pelos cidadãos - diferentemente do que se sucede no âmbito da União Europeia -, os quais podem acionar os Estados-membros diretamente desde que tenham sido exauridas todas as instâncias internas para a resolução de seu conflito ${ }^{35}$.

O TEDH estabeleceu a doutrina da margem de apreciação dos Estados ${ }^{36}$ segundo a qual compete aos Estados-membros da CEDH acatarem e cumprirem as decisões vinculativas e irrevogáveis do TEDH, a partir da especificidade de cada país, ou seja, os Estados-membros têm a liberdade necessária para definirem a melhor forma de cumprirem as decisões do $\mathrm{TEDH}^{37}$ de maneira a não se criar um padrão comum a todos os Estados ${ }^{38}$ - ainda que estes não atuem de maneira ilimitada no que compete a essa prerrogativa ${ }^{39}$. Novamente, verifica-se a diferença em relação à estrutura interna da União Europeia, em que não apenas os objetivos a serem atingidos, mas também os meios para se atingirem tais objetivos, são previamente definidos.

\subsection{A tutela multinível dos direitos fundamentais}

No que diz respeito à proteção dos direitos fundamentais, é de se destacar que, em termos cronológicos, a primeira linha de sua defesa se vincula aos próprios textos constitucionais dos Estados, especialmente porque são com estes que os cidadãos têm contato diretamente. Em segundo lugar, destaca-se a existência da $\mathrm{CEDH}$ que, por meio do TEDH, atua na proteção dos direitos fundamentais dos cidadãos de seus Estados-membros, podendo inclusive o indivíduo, como dito anteriormente, ter acesso direto ao Tribunal. A CDFUE, surgindo em um terceiro momento e sendo aplicada apenas no âmbito da União Europeia e de seus Estados-membros, completa a tutela multinível dos direitos fundamentais no espaço europeu.

Uma vez que o espaço europeu se afigura como composto por três ordens jurídicas distintas no que concerne à defesa dos direitos fundamentais, quais sejam, a nacional (constituições), a europeia (CDFUE) e a internacional $(\mathrm{CEDH})^{40,41}$, torna-se necessário estabelecer claramente a maneira como tais fontes se inter-relacionam, especialmente quando se leva em consideração as competências de cada uma dessas camadas. Além disso, ainda que os direitos previstos nesses documentos sejam inúmeras vezes coincidentes, é de sublinhar que cada um desses sistemas possui especificidades que, em última instância, tornam-nos diferentes entre si, o que deveria trazer como resultado a garantia de níveis diferentes e diferenciados de proteção dos direitos fundamentais ${ }^{42}$.

De maneira sintética, é possível afirmar que a tutela multinível dos direitos fundamentais traz as seguintes vantagens: 1) Uma camada de proteção pode suprir eventuais lacunas de outra (como parece ser o caso claro da proteção dos direitos sociais garantida pelas constituições nacionais e pela CDFUE, mas não 
pela $\mathrm{CEDH}$ ) ; 2) Permite que outras instituições para além do próprio Estado apresentem-se como garantidoras dos direitos fundamentais (de maneira que haja reforço não apenas da tutela dos direitos fundamentais mas também dos mecanismos para sua concretização); 3) Possibilita maiores possibilidades de acesso à justiça por parte dos cidadãos, que passam a contar com outros tribunais além dos nacionais para apreciarem suas demandas ${ }^{43}$.

Contudo, a existência desses diferentes níveis de proteção dos direitos fundamentais - o nacional, o europeu (CDFUE) e o internacional (CEDH) não necessariamente traz apenas vantagens ao cidadão. Torna-se possível, nesse sentido, identificar riscos à tutela multinível dos direitos fundamentais, os quais podem ser resumidos nos seguintes pontos: 1) A multiplicação de catálogos de direitos fundamentais não necessariamente leva a uma maior proteção do cidadão, especialmente devido a eventuais entraves políticos entre as instâncias jurisdicionais envolvidas; 2) Pode haver incerteza, por parte dos cidadãos, acerca de qual catálogo de direitos fundamentais deve ser invocado em seu caso concreto; 3) Ainda que, com mesma designação, a definição do conteúdo dos direitos apresentados nos diferentes catálogos pode ser variável, o que poderia levar a conflito de jurisdições; 4) A existência de vários tribunais pode delongar e encarecer o processo como um todo; 5) Pode haver decisões contraditórias entre os tribunais envolvidos, o que gera desconfiança e falta de aceitação acerca do resultado proferido ${ }^{44}$. Esses riscos poderiam gerar o rebaixamento do nivel de proteção, em direção contrária à que se pretende quando da criação desses distintos catálogos de direitos fundamentais.

\section{OS RISCOS DA TUTELA MULTINÍVEL}

Seria de se imaginar que a existência, no espaço europeu, dos três catálogos de direitos fundamentais apresentados anteriormente tendesse a aumentar o nível de proteção do cidadão. Conforme mostrado, uma das principais vantagens seria a criação de um sistema de "complementação de direitos", em que as ausências verificadas em um sistema jurídico seriam complementadas, ou compensadas, por outro.

Contudo, a proliferação de camadas de proteção pode causar exatamente o efeito oposto, qual seja, o de se diminuir, ou de rebaixar, o nível de proteção dos direitos fundamentais. $\mathrm{O}$ risco em tela corresponde a eventual nivelamento por baixo $0^{45}$ da proteção dos direitos fundamentais, ou seja, à situação na qual determinado Estado reduziria seu próprio nível de proteção ao verificar que outro Estado possui um nível de proteção inferior, de maneira que o primeiro possa competir, em termos socioeconômicos e até mesmo político-jurídicos, com o segundo. Uma das soluções para tal problema seria por meio do diálogo judicial, o qual, porém, parece não ter sido suficiente para se evitar tal situação, como se verá neste tópico. 
3.1 O diálogo judicial como mecanismo para se (tentar) evitar conflitos entre órgãos jurisdicionais

No âmbito de um sistema multinível de tutela dos direitos fundamentais, quantidade não é [necessariamente] qualidade ${ }^{46}$. A ideia de que um grau posterior de tutela dos direitos fundamentais levaria a uma maior proteção pode ser refutada na prática com base nos seguintes pontos:

a) as necessidades de coordenação entre as diferentes camadas jurídicas - a camada legal, ou infraconstitucional, e a camada constitucional, estas no âmbito dos Estados-membros da União Europeia; a camada europeia e ainda a camada internacional -, coordenação esta que nem sempre é bem realizada;

b) as diferenças linguísticas, de maneira que a expressão "liberdade de domicílio" signifique coisas diferentes no âmbito do mesmo ordenamento jurídico - quanto mais em ordenamentos jurídicos que ainda que se apresentem como semelhantes são efetivamente distintos;

c) o fato de que como o estabelecimento de determinado nível de proteção pressupõe a ponderação entre direitos - por não haver direitos absolutos, por um lado, e por ser impossível determinar-se o mínimo quantificável de determinado direito a ser garantido, já que os recursos são escassos, por outro -, não se pode, a priori, estabelecer qual seria o máximo de sua proteção, devendo esta ser estabelecida caso a caso ${ }^{47}$.

A solução apontada pela doutrina para tais problemas está relacionada à ideia de diálogo judicial entre as três camadas de proteção dos direitos fundamentais - nacional, europeia e internacional. Entende-se o diálogo judicial como a situação em que a instância decisória "A" se utiliza dos argumentos oriundos da instância decisória "B" não apenas no sentido de que "A" faria uma citação da jurisprudência de " $B$ " em sua própria jurisprudência, mas sim no sentido de haver uma real utilização, por parte de "A", dos valores e dos princípios oriundos de "B"48. Nesse sentido, a manutenção do diálogo judicial entre os Tribunais envolvidos em determinado caso no espaço europeu se apresenta como fundamental para que haja a necessária troca de informações e de visões de mundo diferentes de maneira a se chegar à melhor proteção possível para o cidadão ${ }^{49}$.

Dessa forma, o diálogo judicial entre tribunais pressupõe o reconhecimento mútuo de suas respectivas competências e âmbitos de atuação de maneira a fazer com que aquele a quem a proteção dos direitos fundamentais se dirige - $\mathrm{O}$ cidadão - não seja prejudicado. Nesse contexto, espera-se que os tribunais não decidam de maneira isolada, mas sim levando em conta, em sua argumentação, o ordenamento jurídico e a jurisprudência já produzida nas outras camadas de decisão ${ }^{50}$, de maneira que um tribunal se aproprie da experiência e dos argumentos utilizados pelo(s) outro(s) em sua própria decisão. No caso específico do espaço europeu, a absorção de princípios e valores diferentes daqueles com os quais determinado juiz já está acostumado pode se fundamentar, para além da jurisprudência dos tribunais, também nas tradições constitucionais comuns aos Estados-membros - tanto da União Europeia quanto da CEDH. 
Importa ressaltar um dos mecanismos formais de diálogo judicial mais importantes no âmbito da União Europeia, qual seja, o previsto no art. 267, TFUE, o chamado processo de questões prejudiciais. Com base nesse artigo, tem-se que os órgãos jurisdicionais ordinários têm a possibilidade de solicitar ao TJUE que se pronuncie a respeito da interpretação dos Tratados e sobre a validade e a interpretação dos atos adotados pelas instituições, órgãos ou organismos da União, enquanto os tribunais constitucionais - entendidos aqui como aqueles a cujas decisões não cabe recurso no âmbito interno dos Estados-membros - têm a obrigação de se dirigir ao TJUE caso surjam tais dúvidas nessas interpretações. $O$ mecanismo estabelece claro diálogo entre o juiz nacional e o juiz europeu a partir do princípio da igualdade - já que não há subordinação de um juiz a outro - e ainda com base no princípio da repartição material de competências, o que, em tese, favorece a proteção dos direitos fundamentais ${ }^{51}$.

Ainda no que concerne às questões prejudiciais, é importante destacar que o mecanismo não pode ficar restrito à mera "consulta", no sentido de o juiz nacional perguntar e o juiz europeu responder. Nesse contexto, importa destacar que o juiz europeu necessita incorporar à sua interpretação os valores e princípios que sejam considerados como inafastáveis pelo juiz nacional, adequando-os àqueles vistos como fundamentais no quadro jurídico da União Europeia $^{52}$ de maneira a se garantir a melhor proteção possível dos direitos do cidadão.

Da mesma maneira, a CEDH mantém o diálogo judicial por meio da margem de apreciação dos Estados, conforme indicado anteriormente nesse texto. Uma vez que são as autoridades nacionais as mais próximas do caso concreto - por serem estas as que mais têm conhecimento acerca de sua própria legislação - e ainda por terem conhecimento acerca das condições, inclusive econômicas, para a colocação em prática de políticas que efetivem as decisões do TEDH, compete a elas a colocação em prática daquilo que for decidido por tal Tribunal. Em suma, o TEDH não impõe mecanismos uniformes para a concretização de suas decisões, devendo cada Parte Contratante da CEDH decidir por aquela que considera a melhor forma de atuar ${ }^{53}$. Por outras palavras, estabelece-se claramente um diálogo a partir do momento em que aos Estados é dada relativa liberdade para pôr em prática aquilo que lhe compete.

A CEDH também estabelece reuniões de trabalho constantes com os juízes nacionais tendo por objetivo o estabelecimento de padrões comuns para a interpretação que levem ao entendimento comum entre os juízes envolvidos. Tais reuniões se apresentam como um mecanismo de autocontenção do TEDH para se tentar evitar decisões contraditórias entre as Cortes envolvidas ${ }^{54}$.

Ainda no âmbito da CEDH, importa destacar o chamado Protocolo $n^{0} 16^{55}$, que busca estabelecer um mecanismo de consulta prévia ao TEDH por parte dos Estados de maneira semelhante ao art. 267, TFUE. Ainda que não tenha o 
caráter de consulta obrigatória e ainda que suas respostas não sejam vinculantes - características específicas do processo das questões prejudiciais -, o Protocolo $n^{\circ} 16$ busca ampliar os canais de colaboração entre os juízes nacionais e os juízes internacionais, ampliando a possibilidade de diálogo judicial para além do momento decisório. Além disso, também no que concerne ao diálogo, destaca-se que os juízes nacionais não são obrigados a cumprir as recomendações oriundas do TEDH decorrentes das consultas com base no Protocolo $\mathrm{n}^{\mathrm{o}} 16$, o que decorre do caráter não vinculante das respostas ${ }^{56}$.

Apesar da presença desses pontos positivos no que diz respeito ao diálogo judicial dentro do triângulo europeu, tal mecanismo também recebe inúmeras críticas a partir da doutrina, especialmente quando se considera que o que ocorre, ao menos no âmbito interno da União Europeia, é a imposição judicial e não o "verdadeiro" diálogo judicial. Ainda que o relacionamento entre o juiz nacional e o juiz europeu se fundamente no princípio da igualdade devido à ausência de hierarquia formal entre um e outro, acaba por haver a centralidade da posição do juiz europeu, nomeadamente do TJUE, passando este a ser o único titular da possibilidade de interpretação do direito europeu devido ao processo de questões prejudiciais previsto no art. 267, $\mathrm{TFUE}^{57}$. Significa dizer que o risco anteriormente percebido de "o juiz nacional pergunta, o juiz europeu decide e o juiz nacional obedece" acaba por se concretizar, em detrimento ao debate, ao diálogo, entre as instâncias envolvidas ${ }^{58}$.

Outra crítica que se faz ao diálogo judicial nos moldes em que este ocorre na atualidade diz respeito à diferença entre diálogo e influência. Nesse sentido, questiona-se se existe efetivo diálogo judicial em situações em que apenas um tribunal se utiliza dos valores e dos princípios do outro sem haver reciprocidade. Por essa perspectiva, não se pode falar em diálogo se não houver interação entre os tribunais, mas apenas influência de um sobre outro, especialmente nos casos em que um tribunal simplesmente se apropria da jurisprudência de tribunais dotados de maior prestígio ${ }^{59}$ ou quando um tribunal efetivamente se submete a outro. Nessas situações, torna-se possível afirmar que não há comparações entre direitos distintos muito menos diálogo entre tribunais, mas sim a simples apropriação por um tribunal daquilo que lhe é mais conveniente para formular a justificativa de sua tomada de posição ou até mesmo para apenas sustentá-la quando esta já estiver definida ${ }^{60}$.

A comprovação prática da ausência de diálogo judicial no âmbito da União Europeia parece estar presente no Parecer 2/13 do TJUE, que analisou as condições de acesso da União à CEDH, tendo-se por base o previsto no art. $6^{\circ}, n^{\circ} 2$, TUE. Ainda que todos os Estados-membros da União Europeia sejam também membros da CEDH e ainda que o Conselho da Europa e a União Europeia tenham "papéis diferentes, mas valores compartilhados" 61 , o TJUE decidiu pela incompatibilidade do Acordo de Adesão da União Europeia à CEDH em fins de 2014, fato este que será analisado a seguir. 


\subsection{A ausência de diálogo judicial entre tribunais: o parecer 2/13}

É nesse contexto - de verdadeira ausência de diálogo judicial entre Tribunais, com consequências que se afiguram como extremamente negativas no que diz respeito à proteção dos direitos fundamentais - que surgiu o Parecer 2/13, proferido pelo Tribunal Pleno do TJUE, em 18 de dezembro de 2014, acerca da possibilidade de acesso da União Europeia à CEDH.

Conforme dito anteriormente, o Tratado de Lisboa trouxe a possibilidade jurídica para que a União Europeia acedesse à CEDH. Vale destacar que o interesse da União Europeia em fazer parte da CEDH não é recente, visto que tal preocupação existia já na década de $1970^{62}$. Por sua vez, em meados da década de 1990, o (então) Tribunal de Justiça das Comunidades Europeias (TJCE) foi instado a se pronunciar acerca da possibilidade de as Comunidades virem a aderir à $\mathrm{CEDH}$ e se tal adesão estaria de acordo com seus Tratados constitutivos. $\mathrm{O}$ TJCE, por meio do Parecer 2/94, "concluiu que a adesão exigiria uma revisão formal dos tratados" ${ }^{63}$, já que as Comunidades não tinham, à época, competência legal para aceder à CEDH.

Tal "revisão formal dos tratados" foi realizada no âmbito do Tratado de Lisboa, o qual trouxe, em seu art. $6^{\circ}, n^{\circ} 2$, que "a União adere à Convenção Europeia para a Proteção dos Direitos do Homem e das Liberdades Fundamentais [...]". Uma vez que a União Europeia adquiriu a possibilidade legal de fazer parte da CEDH com base neste artigo, a Comissão Europeia submeteu ao TJUE um pedido de parecer acerca da legalidade do Acordo de Adesão da União Europeia à CEDH (Acordo de Adesão), sendo questionado, neste pedido, se tal acordo seria compatível com os Tratados da União Europeia. O TJUE, em resposta a tal pedido, informou, no Parecer 2/13, que o Acordo de Adesão, conforme proposto, não é compatível com o art. $6^{\circ}, n^{\circ} 2$ TUE, nem com o Protocolo n 8 relativo à adesão ${ }^{64}$.

Os argumentos do TJUE podem ser sintetizados em quatro pontos principais ${ }^{65}$ :

a) o acordo, conforme redigido, pode vir a lesar algumas características específicas do direito da União, especialmente duas:

- sua autonomia frente a outras ordens jurídicas, especificamente a internacional;

- o princípio da confiança mútua entre os Estados-membros;

b) o acordo pode vir a infringir o art. 344, TFUE ${ }^{66}$, já que não exclui dos Estados-membros a possibilidade destes solucionarem eventuais litígios entre si e/ ou entre estes e a União por meio do TEDH no que concerne à aplicação da $\mathrm{CEDH}$;

c) o acordo não apresenta mecanismos claros para o funcionamento:

- do mecanismo de corresponsável;

- da apreciação prévia de questões internas à União Europeia pelo TJUE de maneira a preservar a uniformidade de seu direito;

d) o acordo permite que um órgão externo à União realize a fiscalização jurisdicional acerca de atos, ações e/ou omissões da União Europeia no que 
concerne à sua Política Externa e de Segurança Comum (PESC), o que poderia fragilizar a uniformidade do direito da União.

O primeiro aspecto a ser levado em consideração no Parecer 2/13 diz respeito à recusa, por parte do TJUE, de permitir aos Estados-membros que estabeleçam níveis de proteção dos direitos fundamentais mais elevados do que aqueles previstos na CDFUE. Neste sentido, o art. 53 da $\mathrm{CEDH}^{67}$ permitiria aos Estados-membros a elevação do nível de proteção, o que, aos olhos do TJUE, poderia infringir "o nível de proteção previsto pela Carta [e também] o primado, a unidade e a efetividade do direito da União" ${ }^{8}$ por não haver no Acordo de Adesão a coordenação entre o art. 53 da CEDH e o art. 53 da CDFUE.

Consequentemente, a possibilidade de eventual proteção dos direitos fundamentais em nível mais elevado, por parte dos Estados-membros, do que o nível previsto pela CDFUE - e principalmente em nível mais elevado do que o nível definido pela interpretação feita pelo TJUE da própria CDFUE com base no primado, na unidade e na efetividade do direito da União - levantaria questões de inconstitucionalidade na atuação dos Estados-membros nesta seara, o que justificaria, a este respeito, a não adesão da União à $\mathrm{CEDH}^{69}$.

Da mesma maneira, na visão do TJUE, outro argumento que poderia infringir o núcleo constitucional da União refere-se à possibilidade de um Estado-membro verificar se outros estão cumprindo com suas obrigações sob a égide do art. 33 da $\mathrm{CEDH}^{70}$. Esta possibilidade, se existente, iria de encontro ao princípio da confiança mútua ${ }^{71}$, o que comprometeria o equilíbrio que fundamenta tanto as relações entre Estados-membros quanto as destes com a União por retirar do TJUE a prerrogativa de realizar a interpretação exclusiva do direito da União a partir do momento em que um Tribunal terceiro - no caso, o TEDH - pudesse decidir a este respeito ${ }^{72}$.

Destaca-se ainda no Parecer 2/13 a ressalva feita pelo TJUE a respeito do Protocolo n ${ }^{\mathrm{o}} 16$ à CEDH. Conforme já dito anteriormente, o Protocolo estabelece um mecanismo de consulta prévia, por parte dos Estados, ao TEDH. Na visão do TJUE, este Protocolo poderia dar aos Estados-membros da União Europeia a possibilidade de buscarem recomendações em outras instâncias que não junto ao próprio TJUE, o que se afigura como obrigatório por meio do art. 267, TFUE. Nesse sentido, caso os Estados-membros assim procedessem - ou seja, caso se utilizassem do previsto no Protocolo n ${ }^{\circ} 16$ e não no art. 267, TFUE -, novamente estariam atuando de maneira inconstitucional, já que estariam violando uma obrigação claramente estabelecida nos Tratados de maneira a enfraquecer sua autonomia e eficácia ${ }^{73}$.

Outro ponto apresentado no Parecer $2 / 13$ e visto como um ponto positivo na defesa do caráter constitucional da União Europeia por parte do TJUE se relaciona ao mecanismo previsto no art. 344, TFUE, que define que os Estados-membros da União Europeia devem se utilizar dos mecanismos internos à União para a solução de conflitos com exclusão de qualquer outro. OTJUE levantou dúvidas acerca da 
coordenação deste artigo com o art. 33 da CEDH, o qual permite a qualquer Parte Contratante submeter ao TEDH violações da Convenção cometidas por outras Partes Contratantes. Dessa maneira, na visão do TJUE, vislumbra-se claramente uma possível violação, em caso de acesso da União Europeia à CEDH, do art. 344, TFUE, já que isto permitiria ao TEDH a interpretação do direito da União, o que - mais uma vez - infringiria os Tratados ${ }^{74}$, especialmente quando se considera o dever de lealdade dos Estados-membros para com a União ${ }^{75}$.

O TJUE também levantou restrições acerca do mecanismo de corresponsável ${ }^{76}$ previsto no Acordo de Adesão. Na proposta apresentada, seria de competência do TEDH a aceitação ou não da presença de determinado Estado-membro da União Europeia, ou dela própria, como corresponsável em determinado litígio ${ }^{77}$. Na visão do TJUE, tal prerrogativa permitiria mais uma vez que um Tribunal externo à União decidisse a respeito do direito da União, infringindo os Tratados ${ }^{78}$.

Além disso, destaca-se a possibilidade de um Estado-membro ser indicado como corresponsável a respeito de alguma reserva que tal Estado-membro poderia ter feito à CEDH com base em seu art. 57, sendo que o Acordo deixa explícito que a adesão da União Europeia à CEDH não pode afetar a situação atual dos Estados-membros em relação à $\mathrm{CEDH}$, especialmente em relação às reservas já estabelecidas $^{79}$.

Por fim, mas ainda a respeito do mecanismo de corresponsável, é importante chamar a atenção para a argumentação do TJUE de que a possibilidade dada pelo Acordo de Adesão ao TEDH para que este definisse eventualmente a responsabilidade a apenas um dos corresponsáveis iniciais também infringiria a jurisdição exclusiva do próprio TJUE acerca da apreciação das responsabilidades entre os Estados-membros e a União ${ }^{80}$.

Outro mecanismo de colaboração previsto no Acordo de Adesão entre a União Europeia e a CEDH refere-se à chamada "apreciação prévia" pelo TJUE. O mecanismo, que se caracteriza por ser um forte incentivo ao diálogo judicial entre os dois Tribunais ${ }^{81}$, funcionaria com o TJUE apreciando, em um momento anterior ao TEDH, os processos a este submetidos em que estivesse em causa o direito da União, mantendo-se assim "as competências da União e as atribuições de suas instituições" ${ }^{82}$. Como se pode perceber, o mecanismo poderia ser utilizado para se evitar a eventual "invasão" da jurisdição do TJUE pelo TEDH. Contudo, o TJUE argumentou que a União precisaria ser informada de maneira completa acerca do processo para que o Tribunal, se fosse o caso, pudesse apreciar a questão por meio das previsões constantes nos Tratados. Mais que isso, porém, o TJUE argumentou que o Acordo de Adesão, conforme proposto, permite a apreciação prévia apenas das questões de validade, e não de interpretação, do direito derivado, o que em consequência infringiria as características da União e de seu direito ${ }^{83}$.

Por fim, o TJUE entendeu que o Acordo de Adesão permitiria a um Tribunal externo à União Europeia - no caso o TEDH - a interpretação do 
direito da União no que concerne à PESC. Ainda que o TJUE reconheça não ter competência jurisdicional a respeito de "alguns atos adotados no âmbito da PESC" ${ }^{84}$, a possibilidade de intervenção de um Tribunal terceiro em assuntos internos da União infringiria sua jurisprudência, que define que a revisão judicial, especialmente aquela relacionada a direitos fundamentais, não pode ser confiada a órgão jurisdicional externo à União ${ }^{85}$.

O Parecer 2/13 foi recebido com inúmeras críticas por parte da doutrina, ainda que também existam vozes que se posicionem favoravelmente. No que concerne aos argumentos favoráveis, de maneira geral, estes se sustentam no caráter constitucional da União Europeia, ou seja, no fato de que o TJUE, ao rechaçar a adesão da União Europeia à CEDH nos termos propostos, estaria defendendo a estrutura interna constitucionalmente estabelecida da União, especialmente no que concerne à divisão de competências entre os Estados-membros e a União, à confiança mútua entre os Estados-membros e à autonomia jurídica da União frente a outras ordens jurídicas - esta última caracterizada especialmente pelo art. 267, TFUE ${ }^{86}$. Em outras palavras, de nada adiantaria a vinculação da União Europeia à CEDH em defesa de direitos fundamentais e humanos se isso fosse feito com base na substituição da atual regulamentação constitucional europeia por outra, especialmente no que concerne à defesa dos direitos fundamentais ${ }^{87}$.

De maneira mais específica, o primeiro ponto importante a ser destacado e que é apontado pela doutrina como correto no Parecer $2 / 13$ vincula-se à importância dada à autonomia do direito da União frente ao direito dos Estados-membros e também frente ao direito internacional ${ }^{88}$. A esse respeito, o TJUE não apenas deixou explícito como também, em inúmeros momentos do Parecer 2/13, enfatizou que o acesso da União Europeia à CEDH não pode ser feita se se infringir o bloco de constitucionalidade da União ${ }^{89}$. Dessa maneira, como o acesso à $\mathrm{CEDH}$, conforme proposto pelo Acordo de Adesão, vincularia o TJUE à interpretação da CEDH feita pelo TEDH - mas sem ocorrer o contrário, como os juízes deixam explícito no parágrafo 185 do Parecer $2 / 13$ - haveria obviamente o surgimento de limites à autonomia do intérprete central do direito da União $0^{90}$.

Nesse sentido, deve-se destacar que, como a legislação europeia é autônoma não apenas em relação ao direito dos Estados-membros, mas também em relação ao direito internacional, as obrigações legais da União Europeia com instituições internacionais não poderiam vir a alterar os princípios centrais de seu próprio arranjo constitucional. Sendo assim, apenas por meio da retenção, por parte do TJUE, da prerrogativa de se analisar o direito da União ${ }^{91}$ é que poder-se-iam manter os princípios do primado e da uniformidade, mantendo-se, em consequência, "a integridade da arquitetura constitucional da União Europeia” ${ }^{\prime 2}$.

Outro ponto importante e que vai ao encontro da defesa da autonomia do direito da União se refere ao princípio da confiança mútua entre os Estados-membros ${ }^{93}$. $\mathrm{O}$ acesso à $\mathrm{CEDH}$ nos moldes propostos permitiria que um Estado-membro fizesse verificações acerca das condições da defesa dos direitos fundamentais em outro Estado-membro, o que infringiria o princípio 
da confiança mútua - não apenas na área criminal, conforme deixa explícito o Parecer 2/13, mas também em outras áreas, como a PESC, além do possível fim do reconhecimento mútuo, entre Estados-membros, de julgamentos e de decisões judiciais ${ }^{94}$ - e, consequentemente, também o princípio da autonomia do direito da União ${ }^{95}$.

Além disso, é importante destacar que é devido a esta autonomia que o TJUE pode ser eventualmente flexível no que concerne ao constitucionalismo multinível no âmbito interno da União Europeia. Por outras palavras, é compreensível o fato de o TJUE eventualmente abrir mão de sua posição quando se relaciona com as Altas Cortes constitucionais dos Estados-membros da União. Por outro lado, o relacionamento entre a mais alta Corte da União Europeia com outros Tribunais é feito de maneira relutante, já que o TJUE não pode renunciar de suas prerrogativas institucionais, especialmente a de guardião da estrutura constitucional da União $0^{96}$.

Em consequência, a partir de uma perspectiva que apresenta o TJUE como verdadeira Corte Constitucional da União Europeia ${ }^{97}$, defende-se que o TJUE está correto em vetar o acesso da União à CEDH. Uma vez que o TJUE tem a competência para analisar questões relacionadas à constitucionalidade no âmbito interno da União, possibilitar o acesso desta à CEDH conforme o Acordo de Adesão proposto efetivamente infringiria os Tratados, especialmente por permitir que um órgão externo - no caso o TEDH, que se tornaria verdadeiro "tribunal constitucional", especialmente no âmbito da PESC - interferisse no direito da União, violando, portanto, os Tratados ${ }^{98}$.

Outro ponto visto como positivo no Parecer $2 / 13$ refere-se ao fato de que, por adiar a entrada da União à CEDH, permite ao TJUE "ganhar tempo" no sentido de consolidar sua jurisprudência a respeito da tutela dos direitos fundamentais. Por outras palavras, argumenta-se que a CEDH já existe há muito tempo, estando sua atuação já consolidada - assim como o TEDH e sua respectiva jurisprudência. Por outro lado, a CDFUE passou a ser vinculante há pouco tempo (quando em comparação com a CEDH), de maneira que o TJUE não teria ainda uma interpretação consolidada em relação à defesa dos direitos fundamentais no espaço da União Europeia. Nesse sentido, o acesso da União à CEDH, nos moldes propostos, poderia trazer como consequência a "absorção" do TJUE pelo TEDH - que já possui "tradição" e legitimidade -, ao menos no que concerne aos direitos fundamentais, o que esvaziaria a função do TJUE e, possivelmente, também a própria CDFUE. Ao negar o acesso nos termos propostos o TJUE, estaria, portanto, por se fortalecer no sentido de buscar estabelecer claramente o grau de vinculação dos Estados-membros aos direitos fundamentais da União em primeiro lugar ${ }^{99}$.

Em resumo, esses são os principais pontos doutrinariamente apresentados como sendo justificadores da decisão do TJUE no Parecer 2/13. Contudo, a despeito da "defesa constitucional dos Tratados" realizada pelo TJUE, é importante ter em mente que o constitucionalismo em si se fundamenta na defesa dos direitos fundamentais, assim como na sujeição do poder público 
à observância de tal defesa ${ }^{100}$. Por outras palavras, não se pode falar na existência de um sistema minimamente constitucional se este não buscar garantir os direitos fundamentais dos cidadãos, os quais, em conjunto, sustentam a dignidade humana - principal vetor de um Estado de direito democrático na atualidade, ou seja, se não houver a defesa dos direitos fundamentais como primeira tarefa do Estado, não se pode falar em existência de algum tipo de constituição, especialmente em seu aspecto material.

Por tal motivo, uma vez que os Tratados correspondem à Constituição material da União Europeia e uma vez que o respeito à dignidade humana é o primeiro dos valores apresentados no art. $2^{\circ}$, TUE, parece ser inconteste que a União precisa, acima de tudo, garantir tal respeito, especialmente por meio da defesa incisiva dos direitos fundamentais. Desta feita, a análise constitucional que deve ser feita acerca do Parecer $2 / 13$ precisa partir do respeito à dignidade humana, ainda mais quando o próprio TUE, em seu Preâmbulo, afirma que "os direitos invioláveis e inalienáveis da pessoa humana" são "valores universais" que fundamentam o "patrimônio cultural, religioso e humanista da Europa". Não foi isso, contudo, o que ocorreu, já que o TJUE colocou os princípios do primado, da unidade e da efetividade do direito da União acima dos direitos fundamentais.

É por isso que a maior parte da doutrina se posicionou de maneira contrária ao Parecer 2/13. Nesse sentido, torna-se possível afirmar que algo está mal colocado quando "a promessa de uma proteção mais efetiva e coerente dos direitos humanos na Europa é rejeitada em favor da autonomia jurídica [da União Europeia]" ${ }^{101}$. Desta feita, as críticas se sustentam no fato de que o Parecer, ao enfatizar constantemente o primado, a unidade e a efetividade do direito da União - ou seja, ao fundamentar-se na ideia de autonomia do direito da União frente a outras ordens jurídicas, tanto internas quanto externas à União -, deixou de lado aquele que é o primeiro valor da União Europeia, qual seja, a dignidade humana, a qual é concretizada por meio da máxima proteção dos direitos fundamentais. Nesse contexto, parece que o TJUE preferiu "priorizar outros princípios constitucionais [...] em detrimento do respeito aos direitos fundamentais", o que, em consequência, enfraquece as "credenciais constitucionais da União Europeia" ${ }^{102}$.

Ao focar-se apenas no aspecto formal e dogmático da autonomia do direito da União, o TJUE acabou por mostrar as fragilidades substantivas dos Tratados em vez de efetivamente preservar seus aspectos constitucionais ${ }^{103}$. Ainda que o Parecer 2/13 reitere que "os direitos fundamentais fazem parte integrante dos princípios gerais do direito da União”, já que o TJUE "inspira-se nas tradições constitucionais comuns aos Estados-Membros, bem como nas indicações fornecidas pelos instrumentos internacionais relativos à proteção dos direitos do Homem em que os Estados-Membros cooperaram ou a que aderiram", e ainda que deixe explícito que "a CEDH reveste um significado particular" nesse contexto de proteção dos direitos fundamentais ${ }^{104}$, está claro, tanto pela leitura do 
Parecer como um todo quanto com base em suas conclusões que a preocupação está em colocar a autonomia do direito da União em primeiro lugar, com os direitos fundamentais aparecendo apenas em segundo plano.

Ao colocar a autonomia em primeiro lugar, o TJUE claramente não realizou o esperado diálogo judicial entre os Tribunais envolvidos, ou seja, não considerou a ideia de tutela multinível no Parecer 2/13, já que o Acordo de Adesão foi criado com base na vontade dos próprios Estados-membros, e estes não foram minimamente consultados acerca de seu eventual posicionamento - e/ou do posicionamento, pelo menos, de seus respectivos Tribunais Constitucionais acerca da adesão.

Ora, uma vez que o TJUE tem vindo a ser verdadeiro Tribunal de direitos humanos, especialmente a partir da entrada em vigor da CDFUE em 2009105, seria de se esperar que o Tribunal desse maior importância axiológica aos direitos fundamentais, colocando-os como o fundamento central no Parecer a partir do qual fortalecer-se-ia a defesa e a proteção dos direitos fundamentais no âmbito da União Europeia em conjunto com a CEDH. Nesse sentido, ainda que não se possa compreender o Parecer como uma simples "política de playground" ${ }^{106}$, torna-se possível afirmar que o TJUE efetivamente errou ao simplesmente dificultar - para não se dizer impedir - a adesão da União Europeia à CEDH.

A leitura do Parecer 2/13 deixa claro que se apresenta como extremamente importante para o TJUE a manutenção da confiança mútua entre os Estados-membros da União Europeia - a ponto deste princípio, que não se encontra presente nos Tratados institutivos da União $0^{107}$, fundamentar parte do Parecer $2 / 13^{108}$. Contudo, o próprio TJUE já havia relativizado este princípio em jurisprudência anterior referente a situações de asilo, permitindo que o Estado-membro "A" verifique as condições em que o asilo é fornecido no Estado-membro " $B$ " antes de enviar o indivíduo para o local. Além disso, é de se destacar que não apenas a jurisprudência do TJUE já estava de acordo com a CEDH e com a jurisprudência do TEDH, mas a própria legislação interna da União havia já sido alterada para estar de acordo com estas duas últimas. Nesse sentido, argumentar que o acesso da União Europeia à CEDH não pode ocorrer porque tal acesso infringiria o princípio da confiança mútua apresenta-se, mais uma vez, como duvidoso e sem bases para prosperar ${ }^{109}$.

É importante ainda destacar outros pontos acerca do Parecer $2 / 13$ que se apresentam de maneira equivocada, já que desconectados do diálogo judicial com vistas à defesa ampla dos direitos fundamentais. Nessa perspectiva, um deles se refere ao argumento desenvolvido pelo TJUE acerca da falta de coordenação entre o art. 344, TFUE, e o art. 33 da CEDH conforme estabelecido no Acordo de Adesão. A esse respeito, destaque-se que o próprio TJUE já havia estabelecido, em jurisprudência anterior (MOX Plant), a possibilidade de coordenação entre os Tratados da União e outra ordem jurídica externa. Naquele caso, o TJUE aceitou a previsão da Convenção das Nações Unidas sobre o Direito do Mar de que os Estados-membros da União Europeia, em caso de disputas entre si, utilizar-se-ão 
do mecanismo previsto no art. 344, TFUE, e não do previsto na Parte XV de tal Convenção para a solução de seus conflitos ${ }^{110}$. Ora, se já há um precedente acerca da relação entre o direito interno da União e o direito internacional na área de proteção ambiental, é razoável acreditar que a adequação entre estas ordens jurídicas também poderia ser realizada, especialmente quando se fala em defesa dos direitos fundamentais.

Por sua vez, no Parecer 2/13, o TJUE destaca que a simples existência da possibilidade de solução de conflitos, por outras vias que não aquelas previstas nos Tratados, já seria motivo suficiente para indeferir o acesso da União Europeia à $\mathrm{CEDH}^{111}$, o que se apresenta como dois pesos diferentes para a mesma medida acerca do mesmo tema. Bastaria, para solucionar este problema, que houvesse a inclusão no Acordo de Adesão de uma cláusula que deixasse explícito que o art. 344, TFUE, tem primazia em relação ao art. 33 da $\mathrm{CEDH}$, garantindo-se, por parte do TEDH, a inadmissibilidade de qualquer reclamação por parte dos Estados-membros da União Europeia que não se utilizassem primeiramente dessa previsão - ficando a Comissão Europeia, inclusive, legitimada a iniciar procedimentos contra os Estados-membros que infringissem tal previsão ${ }^{112}$.

Um último ponto, e talvez o mais importante - que, apesar de sê-lo, foi completamente ignorado no Parecer 2/13 -, diz respeito ao acesso dos cidadãos aos tribunais para a tutela de seus direitos fundamentais. Nesse sentido, importa destacar que o TJUE não se referiu, em nenhum momento, a tal possibilidade, ou seja, não se referiu, em nenhum momento do Parecer 2/13, a eventuais dificuldades que o cidadão pudesse vir a ter a partir do acesso da União Europeia à $\mathrm{CEDH}$, o que pode ser compreendido como um aspecto negativo por não ter tido este Tribunal a sensibilidade para compreender que o ser humano precisa ser colocado em primeiro lugar.

\section{CONCLUSÃO}

A tutela multinível de direitos sociais na União Europeia não é uma garantia de proteção aos direitos de seus cidadãos. Além dos pontos apontados na análise do Parecer, fica claro que, nesse contexto, na situação atual - em que a União Europeia não faz parte da $\mathrm{CEDH}$ - o cidadão pode vir a não ter seu direito tutelado, posto que, conforme o art. 35 da CEDH, o cidadão precisa esgotar todas as vias internas para poder buscar a defesa de seus direitos junto ao TEDH - e, como a União Europeia não faz parte da CEDH, o TEDH não tem jurisdição sobre ela para condená-la. Mais que isso, caso o infrator dos direitos fundamentais seja a União Europeia e/ou uma de suas instituições, o cidadão atualmente irá peticionar contra o Estado-membro da União Europeia que colocou tal ação em prática e não contra a própria União Europeia. Este Estado-membro, contudo, não pode ser condenado, já que não foi ele o infrator do direito fundamental do cidadão. Consequentemente, o cidadão poderia ver seu direito fundamental ser infringido sem ter ninguém a quem 
recorrer ${ }^{113}$. Dessa forma, apenas o acesso da União Europeia à CEDH poderia fazer que o cidadão tivesse efetivamente a garantia de que a eventual violação de um direito fundamental seu pela União Europeia e/ou suas instituições seria devidamente sanada ${ }^{114}$.

Com base no exposto, o que se percebe é que, a despeito dos benefícios decorrentes da tutela multinível dos direitos fundamentais, ainda apresentam-se inúmeros problemas decorrentes da pluralidade de níveis de proteção ${ }^{115}$ - o que inclusive pode ser visto como uma comprovação da aludida falta de diálogo judicial entre os órgãos jurisdicionais no espaço europeu. Uma das maneiras de se solucionar tais problemas é por meio do eventual estabelecimento de margens de apreciação por parte dos Tribunais envolvidos quando estes compartilham responsabilidades ${ }^{116}$ - ou, em outras palavras, corresponde à existência efetiva do diálogo judicial entre os Tribunais envolvidos, mas isso nem sempre se confirma na prática.

\section{REFERÊNCIAS}

BESSELINK, Leonard F. M. The interaction between the EU Charter of Fundamental Rights, the European Convention on Human Rights (ECHR) and National Constitutions. In: FIDE INSTITUTIONAL REPORT, 25., 2012, Tallinn. Annals... Tallinn: Tartu University Press, 2012.

BOBBIO, Norberto. Liberalismo e democracia. São Paulo: Brasiliense, 2000. p. 17-19.

CANOTILHO, Joaquim José Gomes. Direito constitucional e teoria da Constituição. 7. ed. Coimbra: Almedina, 2014.

COSTA, Jean-Paul. On the Legitimacy of the European Court of Human Rights' Judgments. European Constitutional Law Review, United Kingdom, v. 7, n. 2, p. 173-182, 2011.

DAMELE, Giovanni; PALLANTE, Francesco. A tutela multinível dos direitos: quantidade é sinónimo de qualidade? In: MARQUES, A.; BARCELOS, P. Direitos fundamentais e soberania na Europa: história e atualidade. Lisboa: Instituto de Filosofia da Nova, 2014.

DUARTE, Maria Luísa. União Europeia e direitos fundamentais no espaço da internormatividade. AAFDL: Lisboa, 2013.

ESTORNINHO, Maria João. Curso de direito dos contratos públicos: por uma contratação pública sustentável. Coimbra: Almedina, 2014.

GIANNOPOULOS, Christos. Considerations on Protocol no. 16: can the new advisory competence of the European Court of Human Rights breathe new life into the European Convention on Human Rights? German Law Journal, Lexington, v. 16, n. 2, p. 337-350, 2015. 
GRAGL, Paul. Accession revisited: will fundamental rights protection trump the European Union's legal autonomy? In: BENEDEK, Wolfgang et al. (Ed.). European Yearbook on Human Rights. Viena: Neuer Wissenschaftlicher Verlag $\mathrm{GmbH}, 2011$.

. The reasonableness of jealousy: Opinion 2/13 and EU accession to the ECHR. Versão prévia à publicação. In: BENEDEK, Wolfgang et al. (Ed.). European Yearbook on Human Rights. Viena: Neuer Wissenschaftlicher Verlag GmbH, 2015.

GUERRA, Luis López. O sistema europeu de proteção dos direitos humanos. In: GALINDO, George Rodrigo Bandeira; URUEÑA, René; PÉREZ, Aida Torres. Proteção multinível dos direitos humanos. Barcelona: Universitat Pompeu Fabra, 2014. p. 186.

HALBERSTAM, Daniel. "It's the autonomy, stupid!" A modest defense of opinion 2/13 on EU accession to the ECHR, and the way forward. German Law Journal, Lexington, v. 16, n. 1, p. 112, 2015.

HOBSBAWM, Eric J. Era dos Extremos: o breve século XX: 1914-1991. São Paulo: Companhia das Letras, 1995.

JOHANSEN, Stian Øby. The reinterpretation of TFEU Article 344 in Opinion 2/13 and its potential consequences. German Law Journal, Lexington, v. 16, n. 1, p. 169-178, 2015.

KATROUGALOS, George; O'CONNELL, Paul. Fundamental Social Rights. In: TUSHNET, Mark; FLEINER, Thomas; SAUNDERS, Cheryl (Ed.). Routledge Handbook of Constitutional Law. Oxford: Routledge, 2013.

KOMÁREK, Jan. The place of constitutional courts in the EU. European Constitutional Law Review, United Kingdom, v. 9, n. 3, p. 420-450, 2013.

. Why national Constitutional Courts should not embrace EU fundamental rights. LSE Legal Studies Working Paper, n. 23, p. 11, 2014.

KRENN, Christoph. Autonomy and effectiveness as common concerns: a path to ECHR accession after Opinion 2/13. German Law Journal, Lexington, v. 16, n. 1, p. 147-168, 2015.

LAFER, Celso. A reconstrução dos direitos humanos: um diálogo com o pensamento de Hannah Arendt. São Paulo: Companhia das Letras, 1988. p. 20-2.

LAZOWSKI, Adam; WESSEL, Ramses A. When caveats turn into locks: Opinion 2/13 on accession of the European Union to the ECHR. German Law Journal, Lexington, v. 16, n. 1, p. 179-212, 2015.

MARTINS, Ana Maria Guerra; ROQUE, Miguel Prata. A tutela multinível dos direitos fundamentais: a posição do Tribunal Constitucional Português. Conferência Trilateral dos Tribunais Constitucionais Espanhol, Italiano e Português. Santiago de Compostela, Espanha, 16-18 out. 2014. 
MARTINS, Ana Maria Guerra. Constitucionalismo europeu e direitos fundamentais após o Tratado de Lisboa. Estudo elaborado no âmbito das Jornadas sobre o Tratado de Lisboa. 20 jun. 2010.

. Manual de direito da União Europeia. Coimbra: Almedina, 2014.

MATTEUCCI, Nicola. Verbete "direitos humanos". In: BOBBIO, Norberto; MATTEUCCI, Nicola; PASQUINO, Gianfranco. Dicionário de política. Brasília: Universidade de Brasília, 1998.

MENDES, Gilmar Ferreira. Curso de direito constitucional. 9. ed. São Paulo: Saraiva, 2014.

MIRANDA, Jorge. Manual de direito constitucional. Direitos fundamentais. 5. ed. Coimbra: Coimbra, 2014. Tomo IV.

MONIZ, Graca. Vias jurisidicionais para a proteccão do ambiente na Europa. Debater a Europa, Portugal, n. 9, p. 123-158, jul./dez. 2013.

NANOPOULOS, Eva. Killing two birds with one stone? The Court of Justice's opinion on the EU's accession to the ECHR. The Cambridge Law Journal, United kingdom, v. 74, n. 2, p. 187, 2015.

PEERS, Steve. The CJEU and the EU's accession to the ECHR: a clear and present danger to human rights protection. 2014. Disponível em: <eulawanalysis.blogspot.com.br>.

The EU's accession to the ECHR: the dream becomes a nightmare. German Law Journal, Lexington, v. 16, n. 1, p. 213- 222, 2015.

PERNICE, Ingolf; KANITZ, Ralf. Fundamental rights and multilevel constitutionalism in Europe. Berlin: Walter Hallstein-Institut für Europäisches Verfassungsrecht, 2004. WHI Paper 7/04.

PERNICE, Ingolf. Multilevel constitutionalism in the European Union. Berlin: Walter Hallstein-Institut für Europäisches Verfassungsrecht. 2001. WHI Paper 5/02. p. 5.

. The Treaty of Lisbon: multilevel constitutionalism in action. Fevereiro de 2009. Columbia Journal of European Law, Hanover, v. 15, n. 3, p. 349-407, 2009.

QUADROS, Fausto de. Direito da União Europeia. Direito constitucional e administrativo da União Europeia. 3. ed. Coimbra: Almedina, 2013.

ROQUE, Miguel Prata. A dimensão transnacional do direito administrativo: uma visão cosmopolita das situações jurídico-administrativas. Lisboa: AAFDL, 2014.

SARLET, Ingo Wolfgang; FENSTERSEIFER, Tiago. O papel do poder Judiciário brasileiro na tutela e efetivacão dos direitos (e deveres) socioambientais. In: SILVA, Vasco Pereira da; SARLET, Ingo Wolfgang (Org.). Direito público sem fronteiras. Lisboa: Instituto de Ciencias Jurídico-Políticas, 2011. 
SARLET, Ingo Wolfgang; MARINONI, Luiz Guilherme; MITIDIERO, Daniel. Curso de direito constitucional. São Paulo: Revista dos Tribunais, 2012.

SILVA, Suzana Tavares da. Direitos fundamentais na arena global. Coimbra: Imprensa da Universidade de Coimbra, 2011.

TRIBUNAL DE JUSTIÇA DA UNIÃO EUROPEIA. Parecer 2/13 do Tribunal de Justiça (Tribunal Pleno), 18 de dezembro de 2014. Parecer do Tribunal de Justiça (tribunal pleno) de 18 de Dezembro de 2014. Parecer proferido nos termos do art. $218 .^{\circ},{ }^{\circ}{ }^{\circ} 11$, TFUE - Projeto de acordo internacional - Adesão da União Europeia à Convenção Europeia para a Proteção dos Direitos do Homem e das Liberdades Fundamentais - Compatibilidade do referido projeto com os Tratados UE e FUE.

VERGOTTINI, Giuseppe de. El diálogo entre tribunales. Teoría y Realidad Constitucional, Spain, n. 28, 2011.

VOßKUHLE, Andreas. Protection of human rights in the European Union. Multilevel cooperation on human rights between the European Constitutional Courts. Our Common Future, Hannover, nov. 2010.

1 TRIBUNAL DE JUSTIÇA DA UNIÃO EUROPEIA. Parecer 2/13 do Tribunal de Justiça (Tribunal Pleno), 18 de dezembro de 2014. Parecer do Tribunal de Justiça (tribunal pleno) de 18 de dezembro de 2014. Parecer proferido nos termos do art. $218 .^{\circ}$, n. $^{\circ} 11$, TFUE - Projeto de acordo internacional - Adesão da União Europeia à Convenção Europeia para a Proteção dos Direitos do Homem e das Liberdades Fundamentais - Compatibilidade do referido projeto com os Tratados UE e FUE, p. 13, parágrafo 49; p. 35, parágrafo 156.

2 Ver, dentre outros, BOBBIO, Norberto. Liberalismo e democracia. São Paulo: Brasiliense, 2000. p. 17-19; MATTEUCCI, Nicola. Verbete "direitos humanos". In: BOBBIO, Norberto; MATTEUCCI, Nicola; PASQUINO, Gianfranco. Dicionário de política. Brasília: Universidade de Brasília, 1998. p. 353-4; SARLET, Ingo Wolfgang; MARINONI, Luiz Guilherme; MITIDIERO, Daniel. Curso de direito constitucional. São Paulo: Revista dos Tribunais, 2012. p. 258-60; MENDES, Gilmar Ferreira. Curso de direito constitucional. 9. ed. São Paulo: Saraiva, 2014. p. 234-5; MIRANDA, Jorge. Manual de direito constitucional. Direitos fundamentais. 5. ed. Coimbra: Coimbra, 2014. Tomo IV. p. 30-2; CANOTILHO, Joaquim José Gomes. Direito constitucional e teoria da Constituição. 7. ed, Coimbra: Almedina, 2014. p. 384-5.

3 KATROUGALOS, George; O'CONNELL, Paul. Fundamental Social Rights (17 de outubro de 2011). Publicado como "Social and economic rights". In: TUSHNET, Mark; FLEINER, Thomas; SAUNDERS, Cheryl (eds.). Routledge Handbook of Constitutional Law. Oxford: Routledge, 2013, p. 4-5. Chama-se a atenção para o fato de que todas as citações de textos que não estejam redigidos originalmente em português foram feitas pelo autor deste texto, em tradução livre.

4 MATTEUCCI, op. cit., p. 353-4; SARLET; MARINONI; MITIDIERO, op. cit., p. 261-2; MENDES, op. cit., p. 235-6; MIRANDA, op. cit., p. 31-3; CANOTILHO, op. cit., p. 385-6.

5 HOBSBAWM, Eric J. Era dos Extremos: o breve século XX: 1914-1991. São Paulo: Companhia das Letras, 1995.

6 Aqui se faz referência aos chamados direitos de terceira dimensão, tal como a proteção ao meio ambiente, que se vincula não apenas ao indivíduo, mas também à coletividade. Acerca de tais direitos, ver SARLET, Ingo Wolfgang; FENSTERSEIFER, Tiago. O papel do poder Judiciário brasileiro na tutela e efetivação dos direitos (e deveres) socioambientais. In: SILVA, Vasco Pereira da; SARLET, Ingo Wolfgang (orgs.). Direito público sem fronteiras. Lisboa: Instituto de Ciências Jurídico-Políticas, 2011.

7 LAFER, Celso. A reconstrução dos direitos humanos: um diálogo com o pensamento de Hannah Arendt. São Paulo: Companhia das Letras, 1988. p. 20-2. 
8 MARTINS, Ana Maria Guerra; ROQUE, Miguel Prata. A tutela multinível dos direitos fundamentais: a posição do Tribunal Constitucional Português. Conferência Trilateral dos Tribunais Constitucionais Espanhol, Italiano e Português. Santiago de Compostela, Espanha, 16-18 de outubro de 2014, p. 4.

9 Acerca do constitucionalismo multinível ver, por todos, PERNICE, Ingolf. The Treaty of Lisbon: multilevel constitutionalism in action. Fevereiro de 2009. Columbia Journal of European Law, Hanover,v. 15, n. 3 , 2009.

10 Acresça-se a tais identidades a identidade regional, no caso de Estados federados.

11 PERNICE, op. cit., p. 2.

12 Ibidem, p. 4.

13 MARTINS, Ana Maria Guerra. Manual de direito da União Europeia. Coimbra: Almedina, 2014. p. 46.

14 PEERS, Steve. The EU's accession to the ECHR: the dream becomes a nightmare. German Law Journal, Lexington, v. 16, n. 1, p. 215, 2015.

15 PERNICE, Ingolf. Multilevel constitutionalism in the European Union. Berlin: Walter Hallstein-Institut für Europäisches Verfassungsrecht. 2001. WHI Paper 5/02. p. 5.

16 Como foi o caso, em Portugal, do Código dos Contratos Públicos de 2008, que corresponde ao resultado da transposição das Diretivas 2004/17/CE e 2004/18/CE - que tratam da contratação pública - para o ordenamento jurídico português. ESTORNINHO, Maria João. Curso de direito dos contratos públicos: por uma contratação pública sustentável. Coimbra: Almedina, 2014. p. 288-9.

17 PERNICE, op. cit., p. 5.

18 PERNICE, Ingolf. Multilevel constitutionalism in the European Union. Berlin: Walter Hallstein-Institut für Europäisches Verfassungsrecht. 2001. WHI Paper 5/02. p. 5-6.

19 Ibidem, p. 8.

20 MARTINS, Ana Maria Guerra. Manual de direito da União Europeia. Coimbra: Almedina, 2014. p. 42-3.

21 DUARTE, Maria Luísa. União Europeia e direitos fundamentais no espaço da internormatividade.. Lisboa: AAFDL, 2013. p. 437.

22 A eficácia horizontal dos direitos fundamentais (drittwirkung), por não ser o objeto de estudo aqui delineado, não será tratada neste texto.

23 MENDES, Gilmar Ferreira. Curso de direito constitucional. 9. ed. rev. atual. São Paulo: Saraiva, 2014. p. 283-4.

24 MARTINS, Ana Maria Guerra. Constitucionalismo europeu e direitos fundamentais após o Tratado de Lisboa. Estudo elaborado no âmbito das Jornadas sobre o Tratado de Lisboa. 20 de junho de 2010, p. 2-3; MARTINS, Ana Maria Guerra; ROQUE, Miguel Prata. A tutela multinível dos direitos fundamentais: a posição do Tribunal Constitucional Português. Conferência Trilateral dos Tribunais Constitucionais Espanhol, Italiano e Português. Santiago de Compostela, Espanha, 16-18 de outubro de 2014, p. 19-20; PERNICE, Ingolf. The Treaty of Lisbon: multilevel constitutionalism in action. Fevereiro de 2009. Columbia Journal of European Law, Hanover, v. 15, n. 3, p. 401, 2009.

25 MARTINS, Ana Maria Guerra. Manual de direito da União Europeia. Coimbra: Almedina, 2014 p. 456.

26 Ainda que não esteja explícito no texto da Carta, destaca-se que "são destinatários da Carta todas as pessoas que estiverem sob a jurisdição dos Estados-membros, salvo quanto aos direitos que, pela sua natureza, deverão ser considerados como estando intrinsecamente ligados à cidadania da União". É o que afirma QUADROS, Fausto de. Direito da União Europeia. Direito constitucional e administrativo da União Europeia. 3. ed. Coimbra: Almedina, 2013. p. 213. Contudo, o mesmo autor ressalta, à p. 212, que a Carta "está longe de ser a Bill of Rights da União", visto que "para que o fosse, os seus direitos deveriam ser invocáveis na União por todos os cidadãos da União contra qualquer ofensa que contra eles fosse dirigida por qualquer autoridade da União ou dos Estados-membros" - o que, na visão do autor, ainda não ocorre efetivamente.

27 MARTINS, Ana Maria Guerra; ROQUE, Miguel Prata. A tutela multinível dos direitos fundamentais: a posição do Tribunal Constitucional Português. Conferência Trilateral dos Tribunais Constitucionais Espanhol, Italiano e Português. Santiago de Compostela, Espanha, 16-18 de outubro de 2014, p. 23.

28 DUARTE, Maria Luísa. União Europeia e direitos fundamentais no espaço da internormatividade. Reimpressão da primeira edição de 2006. Lisboa: AAFDL, 2013. p. 153-5.

29 PERNICE, Ingolf; KANITZ, Ralf. Fundamental rights and multilevel constitutionalism in Europe. Berlin: Walter Hallstein-Institut für Europäisches Verfassungsrecht, 2004. WHI Paper 7/04. p. 7-8.

30 MARTINS, Ana Maria Guerra; ROQUE, Miguel Prata. A tutela multinível dos direitos fundamentais: a posição do Tribunal Constitucional Português. Conferência Trilateral dos Tribunais Constitucionais Espanhol, Italiano e Português. Santiago de Compostela, Espanha, 16-18 de outubro de 2014, p. 30-1. 
31 Destaca-se que "[e] nquanto a União não aderir à CEDH, nos termos do art. $6 .^{\circ}$, n. $^{\circ} 3$ [sic], do TUE, os direitos fundamentais nela reconhecidos serão aplicados no âmbito da ordem jurídica da União pela via dos princípios gerais, tal como sucedia até a entrada em vigor do TL [Tratado de Lisboa], e ainda na medida em que seja acolhidos pela CDFUE". Ibidem, p. 23.

32 Ibidem.

33 Vale destacar, contudo, que o Tribunal Europeu dos Direitos do Homem (TEDH), por meio de jurisprudência, deu guarida a outros direitos - de segunda e terceira dimensões - que não estão originalmente previstos na $\mathrm{CEDH}$ - tal como o direito a um ambiente saudável - por meio de derivações dos direitos estabelecidos na Convenção - ainda que não de maneira ativista, mas sim como resultado de um consenso desenvolvido ao longo do tempo entre os membros do Conselho da Europa. COSTA, Jean-Paul. On the Legitimacy of the European Court of Human Rights' Judgments. European Constitutional Law Review, United Kingdom, v. 7, n. 2, p. 178, 2011.

34 MARTINS, Ana Maria Guerra; ROQUE, Miguel Prata. A tutela multinível dos direitos fundamentais: a posição do Tribunal Constitucional Português. Conferência Trilateral dos Tribunais Constitucionais Espanhol, Italiano e Português. Santiago de Compostela, Espanha, 16-18 de outubro de 2014. p. 16.

35 COSTA, Jean-Paul. On the Legitimacy of the European Court of Human Rights' Judgments. European Constitutional Law Review, United Kingdom, v. 7, n. 2, p. 179, 2011.; GUERRA, Luis López. O sistema europeu de proteção dos direitos humanos. In: GALINDO, George Rodrigo Bandeira; URUEÑA, René; PÉREZ, Aida Torres. Proteção multinível dos direitos humanos. Barcelona: Universitat Pompeu Fabra, 2014. p. 186.

36 COSTA, op. cit., p. 180; GUERRA, op. cit., p. 198-9.

37 GUERRA, op. cit., p. 191.

38 COSTA, op. cit., p. 180; p. 197.

39 MARTINS; ROQUE, op. cit., p. 18.

40 A estas ordens jurídicas distintas dá-se o nome de triângulo europeu, visto que, em seus vértices, estão as três possibilidades de solução do conflito - a nacional, a europeia e a internacional - e, em seu centro, encontra-se o cidadão - o qual pode se sentir hesitante a respeito de qual deles acionar. Sobre o triângulo europeu ver DUARTE, Maria Luísa. União Europeia e direitos fundamentais no espaço da internormatividade. Reimpressão da primeira edição de 2006. Lisboa: AAFDL, 2013. p. 431-2; MONIZ, Graça. Vias jurisidicionais para a protecção do ambiente na Europa. Debater a Europa, Portugal, n. 9, p. 125-6, jul./ dez. 2013. Utilizando uma nomenclatura diferente ("três pilares") ver PERNICE, Ingolf. The Treaty of Lisbon: multilevel constitutionalism in action. Fevereiro de 2009. Columbia Journal of European Law, Hanover, v. 15, n. 3, p. 401-2, 2009,

41 Há de se destacar que, no âmbito internacional, existe não apenas a $\mathrm{CEDH}$ mas também outros atores, tal como o Tribunal Internacional de Justiça. Desta forma, considerando-se os objetivos deste texto, por nacional, deve-se entender os mecanismos internos aos Estados-membros da União Europeia; por europeu, deve-se entender os mecanismos próprios da União Europeia e, por internacional, deve-se entender os mecanismos relacionados à CEDH e/ou ao TEDH.

42 Nesse sentido KOMÁREK, Jan. Why national Constitutional Courts should not embrace EU fundamental rights. LSE Legal Studies Working Paper, n. 23, p. 11, 2014.

43 MARTINS, Ana Maria Guerra; ROQUE, Miguel Prata. A tutela multinível dos direitos fundamentais: a posição do Tribunal Constitucional Português. Conferência Trilateral dos Tribunais Constitucionais Espanhol, Italiano e Português. Santiago de Compostela, Espanha, 16-18 de outubro de 2014, p. 34.

44 Ibidem, p. 34-5. Nesse mesmo sentido, surge o seguinte questionamento: "como explicar a um cidadão que em decorrência de sua situação se encaixar fora do âmbito de atuação do direito da União Europeia sua liberdade não será protegida, enquanto que, se seu problema estivesse dentro desse mesmo âmbito, seus direitos seriam garantidos - ou vice versa?". PERNICE, Ingolf; KANITZ, Ralf. Fundamental rights and multilevel constitutionalism in Europe. Berlin: Walter Hallstein-Institut für Europäisches Verfassungsrecht. Humboldt-Universität zu Berlin, 2004. WHI Paper 7/04. p. 19.

45 A expressão original seria corrida ao fundo do poço, ou race to the bottom, que corresponde à "tendência para os ordenamentos jurídicos mais garantísticos degradarem, progressivamente, o grau de proteção do 'interesse público' - e, reflexamente, dos direitos fundamentais da maioria dos seus cidadãos". Ver a este respeito ROQUE, Miguel Prata. A dimensão transnacional do direito administrativo. Uma visão cosmopolita das situações jurídico-administrativas. Lisboa: AAFDL, 2014, p. 633, nota 1852.

46 DAMELE, Giovanni; PALLANTE, Francesco. A tutela multinível dos direitos: quantidade é sinónimo de qualidade? In: MARQUES, A.; BARCELOS, P. Direitos fundamentais e soberania na Europa. História e atualidade. Lisboa: Instituto de Filosofia da Nova, 2014. No mesmo sentido ver KOMÁREK, Jan. Why 
national Constitutional Courts should not embrace EU fundamental rights. LSE Legal Studies Working Paper, n. 23, p. 14-16, 2014.

47 DAMELE, Giovanni; PALLANTE, Francesco. A tutela multinível dos direitos: quantidade é sinónimo de qualidade? In: MARQUES, A.; BARCELOS, P. Direitos fundamentais e soberania na Europa. História e atualidade. Lisboa: Instituto de Filosofia da Nova, 2014. p. 259-260.

48 VERGOTTINI, Giuseppe de. El diálogo entre tribunales. Teoría y Realidad Constitucional, Spain, n. 28, p. 345-346, 2011.

49 PERNICE, Ingolf. The Treaty of Lisbon: multilevel constitutionalism in action. Fevereiro de 2009. Columbia Journal of European Law, Hanover, v. 15, n. 3, p. 402, 2009.

50 SILVA, Suzana Tavares da. Direitos fundamentais na arena global. Coimbra: Imprensa da Universidade de Coimbra, 2011. p. 60-2.

51 DUARTE, Maria Luísa. União Europeia e direitos fundamentais no espaço da internormatividade. Reimpressão da primeira edição de 2006. Lisboa: AAFDL, 2013. p. 470. Acerca desse tema ver também PERNICE, Ingolf. The Treaty of Lisbon: multilevel constitutionalism in action. Fevereiro de 2009. Columbia Journal of European Law, Hanover, v. 15, n. 3, p. 402, 2009.

52 DUARTE, op. cit., p. 470; PERNICE, op. cit., p. 404-5.

53 GUERRA, Luis López. O sistema europeu de proteção dos direitos humanos. In: GALINDO, George Rodrigo Bandeira; URUEÑA, René; PÉREZ, Aida Torres. Proteção multinível dos direitos humanos. Barcelona: Universitat Pompeu Fabra, 2014. p. 198-9.

54 COSTA, Jean-Paul. On the Legitimacy of the European Court of Human Rights' Judgments. European Constitutional Law Review, United Kingdom, v. 7, n. 2, p. 182, 2011.

55 É importante que se destaque que o Protocolo $n^{\circ} 16$ ainda não foi ratificado por todos as Partes Contratantes da CEDH e, portanto, ainda não está em vigor.

56 GIANNOPOULOS, Christos. Considerations on Protocol No. 16: can the new advisory competence of the European Court of Human Rights breathe new life into the European Convention on Human Rights? German Law Journal, Lexington, v. 16, n. 2, p. 342, 2015.

57 DAMELE, Giovanni; PALLANTE, Francesco. A tutela multinível dos direitos: quantidade é sinônimo de qualidade? In: MARQUES, A.; BARCELOS, P. Direitos fundamentais e soberania na Europa. História e atualidade. Lisboa: Instituto de Filosofia da Nova, 2014. p. 266.

58 Por outro lado, o próprio TJUE argumentou que essa uniformidade de interpretação é decorrência dos Tratados, que, por um lado, exigem a aplicação do princípio do primado e, por outro, pressupõem o TJUE como instância uniformizadora do direito da União - inclusive para poder concretizar o princípio do primado, em uma espécie de círculo em que um fato reforça o outro.

59 VERGOTTINI, Giuseppe de. El diálogo entre tribunales. Teoría y Realidad Constitucional, Spain, n. 28, p. 349, 2011.

60 Ibidem, p. 358.

61 Título do texto que está em: COUNCIL OF EUROPE. The Council of Europe and the European Union: fifferente roles, shared values. Disponível em: < http://www.coe.int/en/web/portal/european-union>. Acesso em: 21 ago. 2015.

62 MARTINS, Ana Maria Guerra. Manual de direito da União Europeia. Coimbra: Almedina, 2014 p. 262.

63 DUARTE, Maria Luísa. União Europeia e direitos fundamentais no espaço da internormatividade. Reimpressão da primeira edição de 2006. Lisboa: AAFDL, 2013. p. 58.

64 TRIBUNAL DE JUSTIÇA DA UNIÃO EUROPEIA. Parecer 2/13..., op. cit., p. 47.

65 Ibidem, p. 46-7, parágrafo 258.

66 Cuja redação é a seguinte: "Os Estados-Membros comprometem-se a não submeter qualquer diferendo relativo à interpretação ou aplicação dos Tratados a um modo de resolução diverso dos que neles estão previstos".

67 Cuja redação é a seguinte: "Nenhuma das disposições da presente Convenção serán interpretada no sentido de limitar ou prejudicar os direitos do homem e as liberdades fundamentais que tiverem sido reconhecidos de acordo com as leis de qualquer Alta Parte Contratante ou de qualquer outra Convenção em que aquela seja parte".

68 TRIBUNAL DE JUSTIÇA DA UNIÃO EUROPEIA. Parecer 2/13..., op. cit., p. 39, parágrafo 188.

69 Acerca do princípio do primado, ver PERNICE, Ingolf. The Treaty of Lisbon: multilevel constitutionalism in action. Fevereiro de 2009. Columbia Journal of European Law, Hanover, v. 15, n. 3, p. 404, 2009. De importância fundamental para a compreensão deste argumento do TJUE é a seguinte frase deste autor: "Como o respeito por este princípio [do primado do direito da União] por todos os Estados-membros e 
pelas autoridades nacionais é uma condição para o funcionamento da União Europeia, nenhuma exceção [à aplicação do princípio em primeiro lugar] é admitida".

70 Cuja redação é a seguinte: "Qualquer Alta Parte Contratante pode submeter ao Tribunal qualquer violação das disposições da Convenção e dos seus protocolos que creia poder ser imputada a outra Alta Parte Contratante.".

71 O princípio da confiança mútua "impõe [...] que cada um dos Estados-Membros considere, salvo em circunstâncias excecionais, que todos os outros Estados-Membros respeitam o direito da União e, muito em especial, os direitos fundamentais reconhecidos por esse direito". TRIBUNAL DE JUSTIÇA DA UNIÃO EUROPEIA. Parecer 2/13..., op. cit., p. 39, parágrafo 191.

72 GRAGL, Paul. The reasonableness of jealousy: Opinion 2/13 and EU accession to the ECHR. Versão prévia à publicação. In: BENEDEK, Wolfgang; BENOÎT-ROHMER, Florence; KARL, Wolfram; NOWAK, Manfred (eds.). European Yearbook on Human Rights. Viena: Neuer Wissenschaftlicher Verlag GmbH, 2015. p. 2; p. 5; HALBERSTAM, Daniel. "It's the autonomy, stupid!" A modest defense of opinion 2/13 on EU accession to the ECHR, and the way forward. German Law Journal, Lexington, v. 16, n. 1, p. $112,2015$.

73 TRIBUNAL DE JUSTIÇA DA UNIÃO EUROPEIA. Parecer 2/13..., op. cit., p. 40, parágrafos 196-7.

74 TRIBUNAL DE JUSTIÇA DA UNIÃO EUROPEIA. Parecer 2/13..., op. cit., p. 41-2, parágrafos 201-14.

75 GRAGL, op. cit., p. 2; p. 5-6; JOHANSEN, Stian Øby. The reinterpretation of TFEU Article 344 in Opinion 2/13 and its potential consequences. German Law Journal, Lexington, v. 16, n. 1, p. 170-1, 2015.

76 "O mecanismo do corresponsável foi introduzido para «evitar qualquer lacuna no sistema da [CEDH] quanto à participação, à responsabilidade e à oponibilidade», que, tendo em conta as características específicas da União, poderia resultar da sua adesão a esta Convenção. Além disso, este mecanismo tem também por finalidade assegurar que, em conformidade com o que é exigido no art. $1 .^{\circ}$, alínea b), do Protocolo n. $8 \mathrm{UE}$, os recursos interpostos por Estados terceiros e os recursos interpostos por indivíduos sejam dirigidos corretamente contra os Estados-Membros e/ou a União, conforme o caso". TRIBUNAL DE JUSTIÇA DA UNIÃO EUROPEIA. Parecer 2/13..., op. cit., p. 42, parágrafos 215-6.

77 GRAGL, Paul. The reasonableness of jealousy: Opinion 2/13 and EU accession to the ECHR. Versão prévia à publicação. In: BENEDEK, Wolfgang; BENOÎT-ROHMER, Florence; KARL, Wolfram; NOWAK, Manfred (eds.). European Yearbook on Human Rights. Viena: Neuer Wissenschaftlicher Verlag GmbH, 2015, p. 6.

78 TRIBUNAL DE JUSTIÇA DA UNIÃO EUROPEIA. Parecer 2/13..., op. cit., p. 43, parágrafos 222-5.

79 Ibidem, p. 43, parágrafos 226-8.

80 TRIBUNAL DE JUSTIÇA DA UNIÃO EUROPEIA. Parecer 2/13..., op. cit., p. 43-4, parágrafos 229-34.

81 GRAGL, op. cit., p. 6.

82 TRIBUNAL DE JUSTIÇA DA UNIÃO EUROPEIA. Parecer 2/13..., op. cit., p. 44, parágrafo 237.

83 Ibidem, p. 44-5, parágrafos 236-48.

84 Ibidem, p. 46, parágrafo 252.

85 Ibidem, p. 46, parágrafo 254-6.

86 KRENN, Christoph. Autonomy and effectiveness as common concerns: a path to ECHR accession after Opinion 2/13. German Law Journal, Lexington, v. 16, n. 1, p. 148, 2015; GRAGL, Paul. The reasonableness of jealousy: Opinion 2/13 and EU accession to the ECHR. Versão prévia à publicação. In: BENEDEK, Wolfgang; BENOÎT-ROHMER, Florence; KARL, Wolfram; NOWAK, Manfred (eds.). European Yearbook on Human Rights, Viena: Neuer Wissenschaftlicher Verlag GmbH, 2015. p. 4.

87 HALBERSTAM, Daniel. "It's the autonomy, stupid!" A modest defense of opinion 2/13 on EU accession to the ECHR, and the way forward. German Law Journal, Lexington, v. 16, n. 1, p. 107-8, 2015. Neste sentido o autor afirma que "o acesso a um regime específico de direitos [a $\mathrm{CEDH}$ ] não deve ocorrer às custas da natureza constitucional da ordem jurídica da União Europeia”.

88 A autonomia do direito europeu frente a outras ordens jurídicas internacionais está "no coração do TJUE". LAZOWSKI, Adam; WESSEL, Ramses A. When caveats turn into locks: Opinion 2/13 on accession of the European Union to the ECHR. German Law Journal, Lexington, v. 16, n. 1, p. 185, 2015. Ver também KRENN, Christoph. Autonomy and effectiveness as common concerns: a path to ECHR accession after Opinion 2/13. German Law Journal, Lexington, v. 16, n. 1, p. 151-4, 2015.

89 Dentre outros momentos, destaca-se a importância da autonomia no parágrafo 170 do Parecer 2/13, especialmente ao se referir à autonomia na interpretação do grau de proteção dos direitos fundamentais "no quadro da estrutura e dos objetivos da União". TRIBUNAL DE JUSTIÇA DA UNIÃO EUROPEIA. Parecer 2/13..., op. cit., p. 37, parágrafo 170. 
90 LAZOWSKI, Adam; WESSEL, Ramses A. When caveats turn into locks: Opinion 2/13 on accession of the European Union to the ECHR. German Law Journal, Lexington, v. 16, n. 1, p. 189, 2015.

91 E também da prerrogativa de analisar a divisão de competências entre a União e os Estados-membros, o que não poderia ser feito por um Tribunal externo à União. A esse respeito, ver KRENN, Christoph. Autonomy and effectiveness as common concerns: a path to ECHR accession after Opinion 2/13. German Law Journal, Lexington, v. 16, n. 1, p. 151, 2015.

92 HALBERSTAM, Daniel. "It's the autonomy, stupid!" A modest defense of opinion 2/13 on EU accession to the ECHR, and the way forward. German Law Journal, Lexington, v. 16, n. 1, p. 111, 2015. a pp. 1134 o autor complementa que "o [TJUE] vai mostrar solicitude para os acordos internacionais de direitos humanos apenas na medida em estes acordos e seus vários arranjos institucionais não prejudiquem a arquitetura constitucional da União Europeia".

93 TRIBUNAL DE JUSTIÇA DA UNIÃO EUROPEIA. Parecer 2/13 ..., op. cit., p. 40, parágrafo 196.

94 KRENN, op. cit., p. 160.

95 LAZOWSKI, Adam; WESSEL, Ramses A. When caveats turn into locks: Opinion 2/13 on accession of the European Union to the ECHR. German Law Journal, Lexington, v. 16, n. 1, p. 191-2, 2015.

96 HALBERSTAM, Daniel. "It's the autonomy, stupid!" A modest defense of opinion 2/13 on EU accession to the ECHR, and the way forward. German Law Journal, Lexington, v. 16, n. 1, p. 114, 2015.

97 GRAGL, Paul. Accession revisited: will fundamental rights protection trump the European Union's legal autonomy? In: BENEDEK, Wolfgang; BENOÎT-ROHMER, Florence; KARL, Wolfram;NOWAK, Manfred (eds.). European Yearbook on Human Rights. Viena: Neuer Wissenschaftlicher Verlag GmbH, 2011. p. 98; HALBERSTAM, op. cit., p. 145.

98 HALBERSTAM, op. cit., p. 141; LAZOWSKI, Adam; WESSEL, Ramses A. When caveats turn into locks: Opinion 2/13 on accession of the European Union to the ECHR. German Law Journal, Lexington, v. 16, n. 1, p. 202-3, 2015.

99 LAZOWSKI; WESSEL, op. cit., p. 189-90; p, 204.

100 BESSELINK, Leonard F. M. The interaction between the EU Charter of Fundamental Rights, the European Convention on Human Rights (ECHR) and National Constitutions. In: FIDE INSTITUTIONAL REPORT, 25., 2012, Tallinn. Annals... Tallinn: Tartu University Press, 2012. p. 1.

101 GRAGL, Paul. The reasonableness of jealousy: Opinion 2/13 and EU accession to the ECHR. Versão prévia à publicação. In: BENEDEK, Wolfgang; BENOÎT-ROHMER, Florence; KARL, Wolfram; NOWAK, Manfred (Ed.). European Yearbook on Human Rights. Viena: Neuer Wissenschaftlicher Verlag GmbH, 2015. p. 3.

102 NANOPOULOS, Eva. Killing two birds with one stone? The Court of Justice's opinion on the EU's accession to the ECHR. The Cambridge Law Journal, United Kingdom, v. 74, n. 2, p. 187, 2015.

103 Ibidem, p. 187. GRAGL, Paul. The reasonableness of jealousy: Opinion 2/13 and EU accession to the ECHR. Versão prévia à publicação. In: BENEDEK, Wolfgang; BENOÎT-ROHMER, Florence; KARL, Wolfram; NOWAK, Manfred (Ed..). European Yearbook on Human Rights. Viena: Neuer Wissenschaftlicher Verlag GmbH, 2015, p. 8.

104 TRIBUNAL DE JUSTIÇA DA UNIÃO EUROPEIA. Parecer 2/13..., op. cit., p. 10, parágrafo 37.

105 KOMÁREK, Jan. The place of constitutional courts in the EU. European Constitutional Law Review, United Kingdom, v. 9, n. 3, p. 421, 2013.

106 PEERS, Steve. The CJEU and the EU's accession to the ECHR: a clear and present danger to human rights protection. EU Law Analysis. 2014. 18 de dezembro de 2014, p. 7.

107 PEERS, Steve. The EU's accession to the ECHR: the dream becomes a nightmare. German Law Journal, Lexington, v. 16, n. 1, p. 221, 2015.

108 TRIBUNAL DE JUSTIÇA DA UNIÃO EUROPEIA. Parecer 2/13..., op. cit., p. 36, parágrafo 168; p. 39, parágrafo 191; p. 40, parágrafo 194; p. 46, parágrafo 258 (Conclusões do Parecer 2/13).

109 GRAGL, Paul. The reasonableness of jealousy: Opinion 2/13 and EU accession to the ECHR. Versão prévia à publicação. In: BENEDEK, Wolfgang; BENOÎT-ROHMER, Florence; KARL, Wolfram; NOWAK, Manfred (eds.). European Yearbook on Human Rights. Viena: Neuer Wissenschaftlicher Verlag GmbH, 2015. p. 9-10.

110 JOHANSEN, Stian Øby. The reinterpretation of TFEU Article 344 in Opinion 2/13 and its potential consequences. German Law Journal., Lexington, v. 16, n. 1, p. 172-4, 2015.

111 TRIBUNAL DE JUSTIÇA DA UNIÃO EUROPEIA. Parecer 2/13 ..., op. cit., p. 41, parágrafo 208.

112 GRAGL, Paul. The reasonableness of jealousy: Opinion 2/13 and EU accession to the ECHR. Versão prévia à publicação. In: BENEDEK, Wolfgang; BENOÎT-ROHMER, Florence; KARL, Wolfram; NOWAK, 
Manfred (eds.). European Yearbook on Human Rights. Viena: Neuer Wissenschaftlicher Verlag GmbH, 2015. p. 12.

113 GRAGL, Paul. Accession revisited: will fundamental rights protection trump the European Union's legal autonomy? In: BENEDEK, Wolfgang; BENOÎT-ROHMER, Florence; KARL, Wolfram; NOWAK, Manfred (eds.). European Yearbook on Human Rights. Viena: Neuer Wissenschaftlicher Verlag GmbH, 2011. p. 70. Vale destacar que o TJUE analisou, em seu Parecer 2/13, o mecanismo das questões prejudiciais e o do corresponsável nas eventuais petições acerca dos direitos fundamentais em relação ao TEDH. Contudo, fez esta análise tendo-se em conta a autonomia do direito da União e não as eventuais facilidades - ou dificuldades - que poderiam ter os cidadãos no momento de acesso ao TEDH para a defesa de seus direitos fundamentais caso estes viessem a ser infringidos pela própria União.

114 Ibidem, p. 2.

115 VOßKUHLE, Andreas. Protection of human rights in the European Union. Multilevel cooperation on human rights between the European Constitutional Courts. Our Common Future, Hannover, 4 de novembro de 2010, p. 3-4.

116 Ibidem, p. 4.

\title{
THE INEFFICACY OF THE MULTILEVEL PROTECTION OF SOCIAL RIGHTS IN THE EUROPEAN UNION
}

\begin{abstract}
The existence of three separate levels of protection of social rights in the European Union - international, regional and national - leads to the assumption that there are countless advantages in such juridical arrangement. In short, one could affirm that there would be a true complementarity among said systems, since the insufficiencies of one of them could be overcome by another one. However, the system involves risks, especially when considering that such legal orders, because they are distinct and will not always be in harmony, even if they make use of the same concepts. In such sense, the main goal of this article is to analyze some of the risks relating to the multilevel protection of fundamental rights, focusing on social rights. Methodologically, first we analyze the emergence of the multilevel protection of fundamental rights and its theories, so that, afterwards we present the risks of multilevel protection, especially the ones deriving from the lack of judicial dialogue among the courts involved.
\end{abstract}

Keywords: Multilevel protection. European Union. Social rights. Advisory Opinion 2/13.

Submetido: 6 jun. 2016

Aprovado: 26 jun. 2016 